\title{
Análise da correlação entre conforto e desempenho térmico em habitações de interesse social por simulação computacional
}

\author{
Analysis of the correlation between comfort and thermal \\ performance in social housing using computer simulation
}

\section{Tássio Luiz dos Santos \\ Fernando Henrique Fiirst dos Santos Porto Arthur Santos Silva}

\section{Resumo}

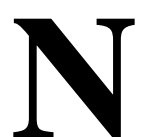

o Brasil, a NBR 15220-3 foi a primeira norma que tratou sobre o tema desempenho térmico em habitações, seguida da NBR 155751 , que apresenta dois métodos normativos para essa avaliação. Desses dois métodos, a simulação computacional é a mais indicada para a avaliação de desempenho térmico por analisar a edificação como um todo. Entretanto, o método não considera parâmetros de conforto térmico, pois o indicador de desempenho baseia-se somente nas diferenças de temperatura do ar. O objetivo deste trabalho é investigar correlações e divergências de desempenho térmico avaliado pelo método de simulação da NBR 15575-1, e o conforto térmico dos usuários de habitações de interesse social com base no modelo adaptativo. Para tanto, um projeto de habitação de interesse social foi simulado em cenários distintos e com configurações de envoltória diferentes, por meio de um experimento fatorial, e sob as mesmas circunstâncias foram feitas análises de sensibilidade das variáveis de entrada. Os resultados mostraram certa correlação entre o desempenho e o conforto térmico em alguns cenários, que pode ser justificada pelo fato de parte das variáveis mais influentes no desempenho ser a mesma no conforto, porém, é evidente a não eficácia do método normativo diante do conforto térmico.

Palavras-chave: Desempenho térmico. Conforto térmico. Simulação computacional. Habitação social. Análise de sensibilidade.

\begin{abstract}
In Brazil, thermal performance standards for buildings were created to improve the quality of buildings in the country. The NBR 15220-3 was the first technical standard to include the topic of thermal performance, followed by NBR 15575-1, which establishes three methods for that purpose. Building simulation is the most suitable method for evaluating thermal performance, since it analyses the building as a whole object. However, one limitation of the simulation method proposed by the standard is that it does not use thermal comfort indices, but only air temperature differences. The aim of this study is to investigate correlations and divergences of thermal performance, evaluated by the simulation method prescribed by NBR 15575, and adaptive thermal comfort. A social housing project was simulated in different scenarios and with different envelope configurations, using a factorial experiment and, under the same circumstances, a sensitivity analysis of the input variables was performed. The results showed correlation between thermal performance and comfort in some scenarios, which can be explained by the fact that part of the most influential variables in thermal performance were the same as in thermal comfort. However the inefficacy of the normative method is evident with regards to thermal comfort.
\end{abstract}

Recebido em 05/03/19 Aceito em 28/05/19
Keywords: Thermal performance. Thermal comfort. Building simulation. Social housing. Sensitivity analysis.

DOS SANTOS, T. L.; PORTO , F. H. F. dos S.; SILVA, A. S. Análise da correlação entre conforto e desempenho térmico em habitações de interesse social por simulação computacional. Ambiente Construído, Porto Alegre, v. 20, n. 2, p. 211-229, abr./ jun. 2020.

ISSN 1678-8621 Associação Nacional de Tecnologia do Ambiente Construído. http:// dx. doi. org/ 10.1590/ s1678-86212020000200396 


\section{Introdução}

As habitações de interesse social (HIS) no Brasil são projetadas para ser construídas em grande escala, de forma a reproduzir um mesmo sistema construtivo em diferentes localidades independentemente do clima da região. Com o objetivo de minimizar os custos para a produção de cada unidade habitacional, essas edificações possuem baixo padrão construtivo, o que, na maior parte das vezes, resulta em um desempenho térmico insatisfatório, que não atende ao conforto térmico dos usuários (MORENO; MORAIS; SOUZA, 2017).

A NBR 15220-3 (ABNT, 2005b) foi o primeiro documento normativo a tratar sobre o tema do desempenho térmico de habitações no Brasil ao trazer diretrizes construtivas para habitações de interesse social de até três pavimentos, conforme o zoneamento bioclimático estabelecido pela parte 3 da norma. As diretrizes construtivas, segundo a norma, são definidas de acordo com as características climáticas do local, com base na Carta Bioclimática adaptada do diagrama de Givoni (1992). Ainda na introdução, a NBR 15220-3 (ABNT, 2005b) recomenda a avaliação do projeto por meio de simulação computacional, mesmo não estabelecendo um procedimento para isso.

Recentemente se elaborou o Regulamento Técnico da Qualidade para o Nível de Eficiência Energética de Edificações Residenciais (RTQ-R) (INSTITUTO..., 2012), publicado em 2010 e atualizado em 2012, que apresenta requisitos para a avaliação do desempenho termoenergético de edificações residenciais. O regulamento estabelece dois métodos para a avaliação do desempenho térmico da envoltória da edificação: o prescritivo e a simulação computacional. O método prescritivo define uma equação de regressão linear multivariada para a pontuação baseada nas características técnicas e construtivas dos projetos.

O método de simulação computacional estabelece parâmetros de entrada para uma simulação termoenergética, tais como o tipo de programa, o número de horas de simulação, detalhes acerca do arquivo climático e os parâmetros de saída. Os resultados da simulação devem ser comparados com os valores tabelados de níveis de desempenho energético, publicados no sítio do PBE Edifica.

Em 2013 foi atualizada a NBR 15575-1 (ABNT, 2013) - a primeira versão foi publicada em 2008 -, que estabelece os requisitos mínimos de desempenho, de vida útil e de garantia para os principais sistemas de uma edificação habitacional. No item 11 da parte 1 são estabelecidos dois métodos, guarnecidos por mais um informativo, para a avaliação do desempenho térmico. São eles: simplificado (normativo), simulação computacional (normativo) e por medição (apenas informativo). O método simplificado prescreve limites para as características térmicas dos componentes construtivos da envoltória, definidos em partes separadas da norma, de acordo com cada sistema (e.g., paredes, coberturas, pisos). O método de simulação possibilita ao projetista avaliar o desempenho térmico da edificação como um todo, quando comparado ao método simplificado.

Chvatal (2014) ressalta a incoerência entre os dois métodos em trabalhos realizados anteriormente e analisa as razões das incongruências. A autora evidenciou que o método simplificado não representa corretamente os impactos da transmitância térmica e da absortância solar da envoltória quando comparado com o método de simulação, o que pode resultar em uma classificação equivocada.

Comparada ao método simplificado, a simulação computacional atua de forma mais abrangente, sendo o método mais indicado para a avaliação termoenergética de um projeto (SORGATO et al., 2014). Por esse motivo, os programas de simulação vêm sendo utilizados com mais frequência, pois possibilitam a entrada de dados (variáveis da edificação e do clima), para estimar adequadamente as saídas como consumo energético, desempenho térmico e até mesmo conforto térmico dos usuários.

Mesmo a simulação computacional sendo mais abrangente, Sorgato et al. (2012) apontam falhas no procedimento de avaliação da NBR 15575 e propõem sugestões para complementar o método e deixá-lo mais eficaz. Uma das críticas sobre o procedimento de simulação é que o desempenho térmico é analisado pela diferença entre a temperatura interna dos ambientes de permanência prolongada e a temperatura externa da edificação. Dessa maneira, a norma não leva em consideração, de forma direta, o conforto térmico do usuário da habitação.

Santo, Alvarez e Nico-Rodrigues (2014) afirmam que a NBR 15575-1 (ABNT, 2013) representa um considerável avanço na busca pela melhoria na qualidade da construção civil brasileira, contudo também assinalam que os critérios relativos ao desempenho térmico adotados pela norma são inadequados, por simplicidade no processo de avaliação de desempenho e ausência de relação com referências de conforto térmico dos usuários. 
Pereira e Ferreira (2014), em uma avaliação dos impactos da NBR 15575-1 (ABNT, 2013) no conforto térmico e no consumo de energia das habitações de interesse social brasileiras, asseveram que a abordagem do método de simulação não foi apropriada para avaliar o conforto térmico dos ocupantes. Em outro estudo, Oliveira, Souza e da Silva (2017) observaram que o atendimento aos requisitos normativos nem sempre garante condições de conforto térmico.

Um levantamento na literatura constatou que o conforto térmico é classificado pelos ocupantes de um prédio como um dos principais propósitos do ambiente e que, entre as diferentes questões de conforto ambiental, o quesito "térmico" foi o mais importante (YANG; YAN; LAM, 2014; FRONTCZAK; WARGOCKI, 2011). Um dos métodos mais utilizados para a análise de conforto térmico nas edificações é o modelo adaptativo proposto pela norma ASHRAE 55 (AMREICAN..., 2017). O objetivo dessa norma internacional é especificar fatores ambientais e pessoais que proporcionem condições térmicas internas aceitáveis para a maioria dos usuários de determinado ambiente. O modelo permite avaliar o conforto térmico de edificações com ventilação natural ou condicionadas artificialmente.

Oliveira, Souza e da Silva (2017) discutiram as normas brasileiras referentes ao desempenho térmico de edificações e concluíram que o método de simulação proposto pela NBR 15575-1 (ABNT, 2013) não se mostrou efetivo para garantir o conforto térmico dos usuários. De fato, Oliveira et al. (2015) avaliaram, para as oito zonas bioclimáticas do Brasil, um modelo de edificação multifamiliar com paredes de concreto. Por meio da simulação computacional, observaram que algumas unidades habitacionais, mesmo atendendo ao nível mínimo de desempenho térmico segundo a NBR 15575-1 (ABNT, 2013), não proporcionaram condições adequadas de conforto térmico.

O método de simulação da NBR 15575-1 (ABNT, 2013) também é criticado por não definir alguns parâmetros de entrada essenciais para garantir a imparcialidade da avaliação térmica da edificação. Estudos de análise de sensibilidade e incertezas já realizados, com grande quantidade de simulações de um mesmo projeto, demonstram que os "analistas" podem, de alguma forma, interferir diretamente nos resultados (SILVA et al., 2014; SILVA; ALMEIDA; GHISI, 2017; SORGATO et al., 2014).

É importante ressaltar que a simulação computacional é uma ferramenta que possui uma grande quantidade de variáveis independentes, que podem ser inseridas em um processo de avaliação de acordo com uma norma ou regulamento adotado; os métodos de avaliação, por sua vez, divergem entre si conforme os parâmetros de entrada ou os métodos de classificação. A análise de sensibilidade ajuda a compreender a propagação de incertezas nos resultados, o que indica ainda a ordem de importância das variáveis independentes em uma simulação (SILVA; ALMEIDA; GHISI, 2017).

Bre et al. (2016) utilizaram a análise de sensibilidade para determinar o conjunto de características arquitetônicas que têm maior influência no desempenho térmico e energético de uma tipologia arquitetônica típica de uma região da Argentina. Dessa forma, através de algoritmos genéticos, determinaram as melhores combinações arquitetônicas para a edificação analisada.

Em outra análise de incertezas, Silva et al. (2014) aplicaram a Análise de Variância para observar quais variáveis independentes do método de simulação da NBR 15575-1 (ABNT, 2013) tinham maior influência no nível de desempenho térmico de uma habitação de interesse social. Os autores ressaltaram que o analista responsável pela modelagem da simulação pode interferir de forma parcial no resultado final ao alterar alguns parâmetros com maior grau de incerteza, pois o método atual da NBR 15575-1 (ABNT, 2013) não coloca restrições para isso.

A Análise de Variância, conhecida também como ANOVA (Analysis of Variance), é um método estatístico que possibilita analisar o grau de variação de cada variável de entrada de um modelo e, assim, investigar a interação entre as variáveis independentes e as variáveis dependentes. Esse método se apresentou eficaz na análise de incertezas de projetos em diferentes trabalhos (e.g., MECHRI; CAPOZZOLLI; CORRADO, 2010; CAPOZZOLI ; GORRINO; CORRADO, 2013; LAM; GE; FAZIO, 2016). Dessa maneira, pode-se observar a importância da análise de sensibilidade na verificação da influência das variáveis de entrada de um modelo computacional de uma edificação, seja no desempenho térmico e energético, seja no conforto ambiental dos usuários.

O método de simulação computacional para a avaliação do desempenho térmico de habitações proposto pela NBR 15575-1 (ABNT, 2013) vem sendo criticado pela comunidade científica desde sua publicação. Como a norma está passando por outra revisão, é importante contribuir com análises técnicas sobre a aplicação de seus métodos neste momento. 
Com base nos estudos e problemáticas apresentados, este trabalho tem o objetivo de investigar as correlações e divergências entre o desempenho térmico, avaliado pelo método de simulação da NBR 15575-1 (ABNT, 2013), e o conforto térmico dos usuários de habitações de interesse social com base no modelo adaptativo.

\section{Método \\ Objeto de estudo}

O objeto escolhido para o estudo é um projeto padrão de 41,66 m² do "Programa Minha Casa, Minha Vida 2 (PMCMV 2) sub 50”, que envolve a construção de habitações de interesse social nas cidades com população menor do que 50 mil habitantes. O projeto apresentado foi obtido na Agência Estadual de Habitação Popular de Mato Grosso do Sul (Agehab) e está sendo executado por todo o estado de MS, já tendo atingido 53 municípios com as características descritas pelo "PMCMV 2 sub 50", sendo 23 na Zona Bioclimática 3, 16 na Zona Bioclimática 5, 13 na Zona Bioclimática 6 e apenas 1 na Zona Bioclimática 8.

Para efeitos de modelagem geométrica da edificação, foram definidos cinco ambientes: quarto de solteiro, cozinha, banheiro, quarto casal e sala. O leiaute do projeto é apresentado na Figura 1. A orientação norte não é apresentada por ser uma das variáveis independentes.

\section{Modelagem computacional}

O programa de simulação utilizado foi o EnergyPlus versão 8.9.0. O comportamento do projeto da edificação foi avaliado para as quatro zonas bioclimáticas do estado do Mato Grosso do Sul. Cada uma dessas zonas bioclimáticas foi representada por uma das cidades em que o projeto apresentado foi implantado. O critério de seleção das cidades foi a quantidade de habitantes, sendo escolhida a cidade da zona bioclimática que tivesse a maior quantidade. As cidades e suas zonas bioclimáticas são apresentadas na Tabela 1.

Para analisar o comportamento dos projetos da edificação em cada zona bioclimática, dois modelos computacionais foram criados: um para determinar o desempenho térmico da envoltória e outro para avaliar o conforto térmico dos usuários.

\section{Figura 1 - (a) Perspectiva isométrica da modelagem da geometria para simulação; e (b) leiaute da planta com dimensões das zonas térmicas destacando os ambientes de permanência prolongada, analisados em azul}

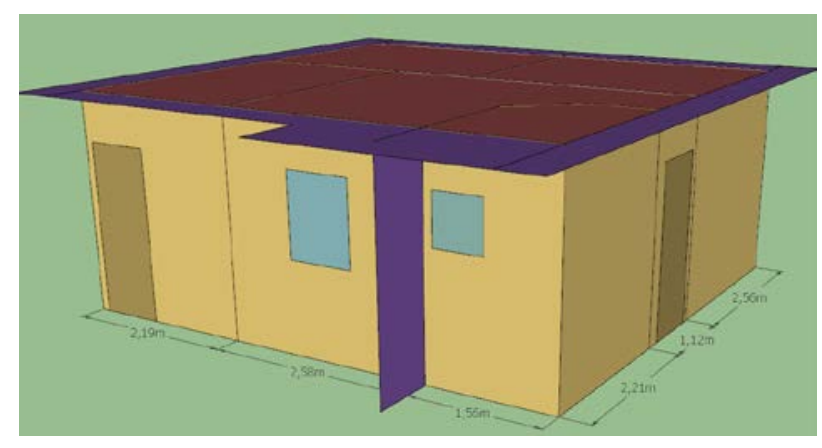

(a)

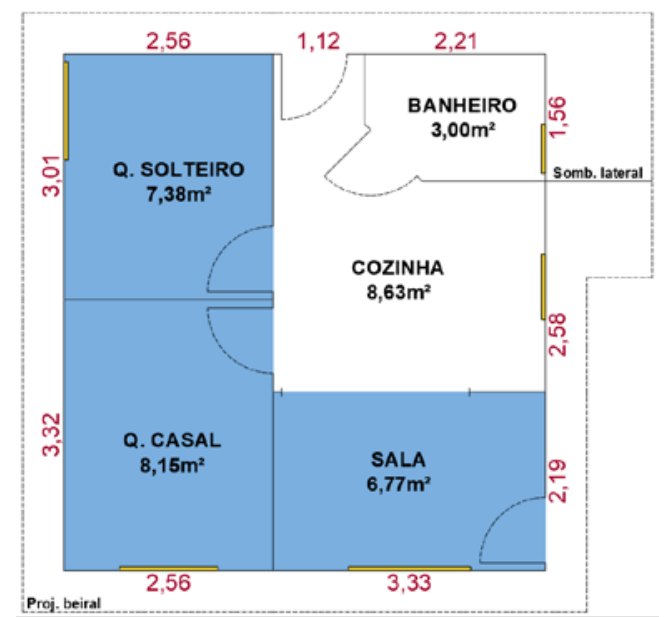

(b)

Tabela 1 - Cidades e zonas bioclimáticas avaliadas em Mato Grosso do Sul

\begin{tabular}{c|c}
\hline Cidade & Zona Bioclimática \\
\hline Coxim & 6 \\
Ladário* $^{*}$ & 8 \\
Juti & 3 \\
Sidrolândia & 5 \\
\hline
\end{tabular}

Nota: *para a cidade de Ladário foi utilizado o arquivo climático de Corumbá. 


\section{Modelagem da simulação do desempenho térmico}

O modelo para a avaliação do desempenho térmico foi elaborado de acordo com o método da NBR 15575-1 (ABNT, 2013). A norma estabelece um nível de ventilação de uma troca de ar por hora em cada ambiente e ausência de cargas internas de qualquer tipo, além de simular o modelo apenas para um dia típico de projeto de verão e outro para inverno.

Os dias típicos foram definidos de acordo com a metodologia descrita pelo Handbook Fundamentals (AMERICAN..., 1993 ${ }^{1}$ apud GOULART; LAMBERTS; FIRMINO, 1998), com base nos arquivos climáticos disponibilizados pelo Inmet para cada cidade. As frequências de ocorrências de temperatura adotadas para a definição das datas foram as mais próximas de 2,5\% para verão e de 97,5\% para inverno. A Tabela 2 apresenta os principais dados dos dias típicos adotados no trabalho.

O contato da edificação com o solo foi configurado e simulado por meio do objeto GroundDomain do programa EnergyPlus. Esse objeto é capaz de processar diferentes configurações de pisos e baseia-se no modelo de diferenças finitas para obter as temperaturas do solo (MAZZEFERRO; MELO; LAMBERTS, 2015).

A troca de ar dos ambientes foi modelada por meio do objeto ZoneVentilation:DesignFlowRate do EnergyPlus. Este método considera apenas um padrão de troca de ar para cada zona, não atende a modelos com sistemas de ventilação mais avançados, com infiltrações diferenciadas nas aberturas dos ambientes, por exemplo, e não considera as condições de ventilação local.

\section{Modelagem da simulação do conforto térmico}

Para a avaliação do conforto térmico, o modelo de simulação foi elaborado de acordo com o método de simulação estabelecido pelo Regulamento Técnico da Qualidade para o Nível de Eficiência Energética de Edificações Residenciais (RTQ-R) (INSTITUTO..., 2012), considerando os ganhos internos da edificação de ocupação, iluminação e equipamentos. Assim como a avaliação do desempenho térmico, o contato com o solo foi configurado por meio do objeto GroundDomain.

Os arquivos climáticos utilizados para a criação do dia típico e para as simulações anuais foram disponibilizados pelo Inmet, em extensão "epw", no site do programa EnergyPlus. As principais informações climáticas das cidades são apresentadas na Figura 2, com valores para um dia médio em cada mês oriundos do arquivo climático. Na figura estão as temperaturas de bulbo seco e bulbo úmido, cujos valores estão no eixo vertical à direita, enquanto a radiação solar global, direta, e a umidade relativa do ar têm seus valores representados no eixo vertical à esquerda.

Tabela 2 - Características dos dias típicos adotados para as simulações de desempenho térmico

\begin{tabular}{l|c|c|c|c|c|}
\cline { 2 - 5 } & Unidade & Ladário & Coxim & Juti & Sidrolândia \\
\hline Nível de Frequência & $\%$ & 2,47 & 2,47 & 2,47 & 2,47 \\
\hline Data & - & $10 / 12$ & $9 / 9$ & $25 / 11$ & $2 / 11$ \\
\hline Temp. Máx. B. Seco & ${ }^{\circ} \mathrm{C}$ & 38,5 & 38,3 & 35,0 & 33,4 \\
\hline Amplitude Térm. B. Seco & ${ }^{\circ} \mathrm{C}$ & 10,1 & 17,4 & 11,8 & 8,6 \\
\hline Ponto de Orvalho & ${ }^{\circ} \mathrm{C}$ & 22,1 & 23,0 & 22,4 & 21,7 \\
\hline Pressão Atmosférica & $\mathrm{Pa}$ & 98.989 & 98.393 & 96.445 & 95.522 \\
\hline Vel. do Vento & $\mathrm{m} / \mathrm{s}$ & 1,70 & 1,41 & 1,74 & 2,21 \\
\hline Dir. do Vento (Az.) & $\mathrm{graus}$ & 131 & 172 & 107 & 269 \\
\hline Nível de Frequência & $\%$ & 97,53 & 97,53 & 97,53 & 97,53 \\
\hline Data & - & $29 / 5$ & $31 / 5$ & $23 / 7$ & $23 / 7$ \\
\hline Temp. Máx. B. Seco & ${ }^{\circ} \mathrm{C}$ & 17,6 & 24,4 & 14,5 & 14,9 \\
\hline Amplitude Térm. B. Seco & ${ }^{\circ} \mathrm{C}$ & 4,0 & 9,9 & 5,0 & 6,2 \\
\hline Ponto de Orvalho & ${ }^{\circ} \mathrm{C}$ & 10,6 & 18,4 & 13,1 & 14,0 \\
\hline Pressão Atmosférica & $\mathrm{Pa}$ & 100.831 & 99.104 & 97.307 & 96.118 \\
\hline Vel. do Vento & $\mathrm{m} / \mathrm{s}$ & 3,46 & 1,32 & 0,00 & 3,14 \\
\hline Dir. do Vento (Az.) & $\mathrm{graus}$ & 198 & 196 & 204 & 164 \\
\hline
\end{tabular}

${ }^{1}$ AMERICAN SOCIETY OF HEATING, REFRIGERATING AND AIR-CONDITIONING ENGINEERS. Weather Data and Design Conditions. In:ASHRAE HANDBOOK - FUNDAMENTALS. New York, 1993. 

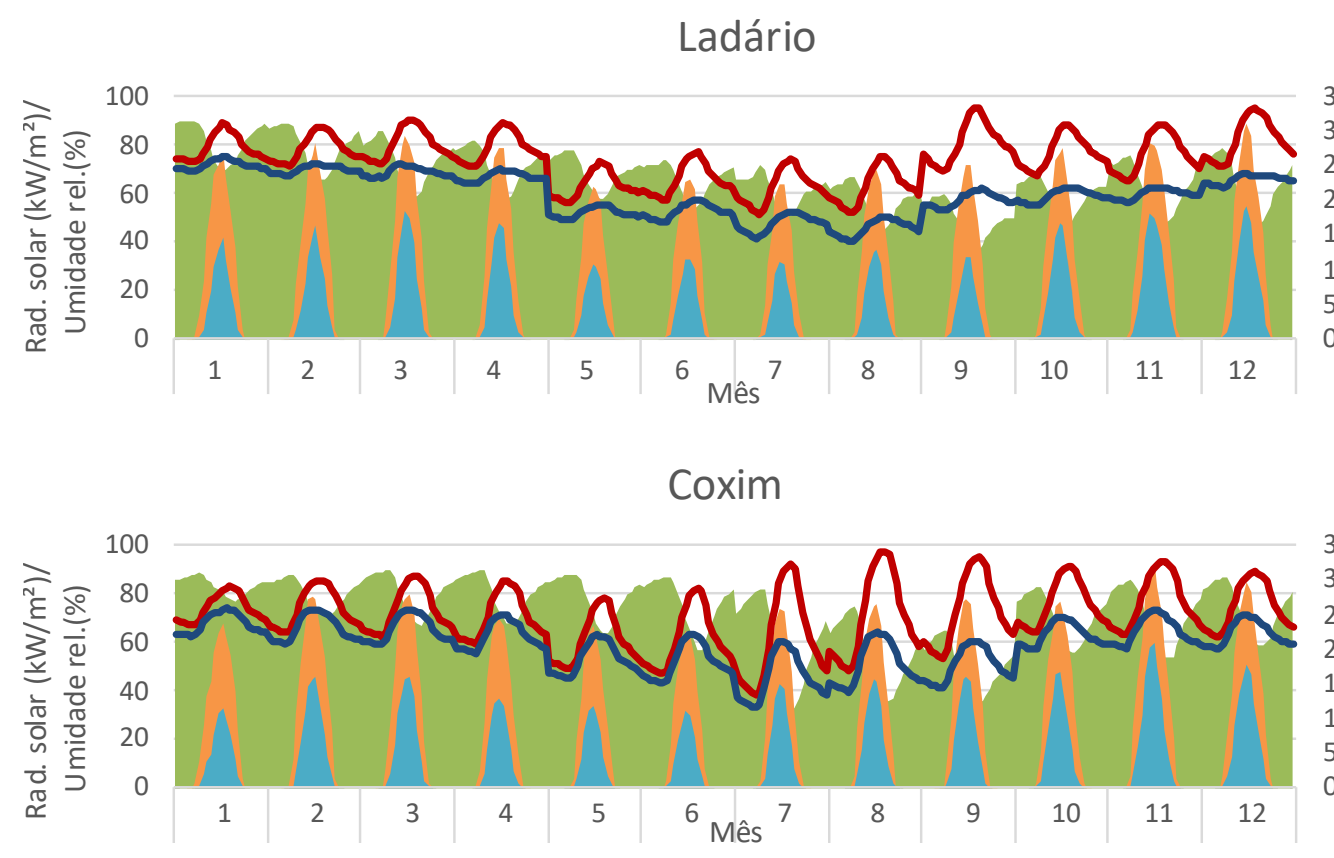

Juti

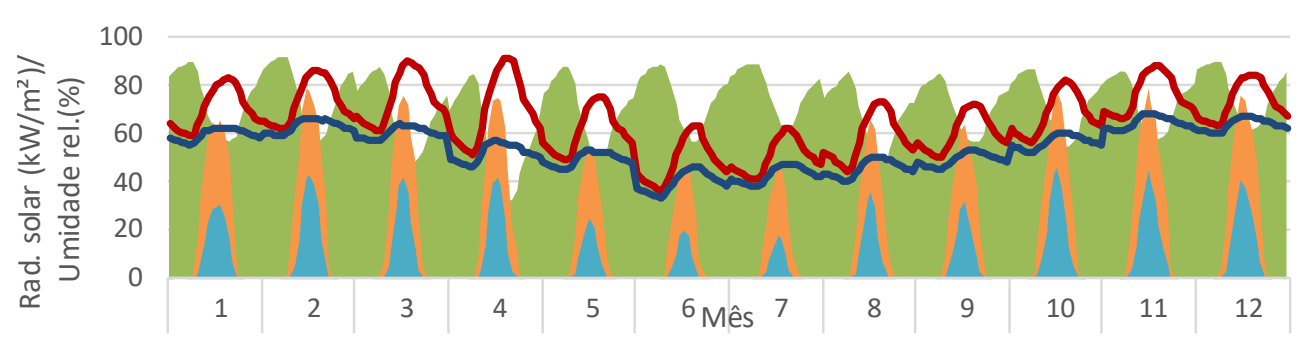

\section{Sidrolândia}

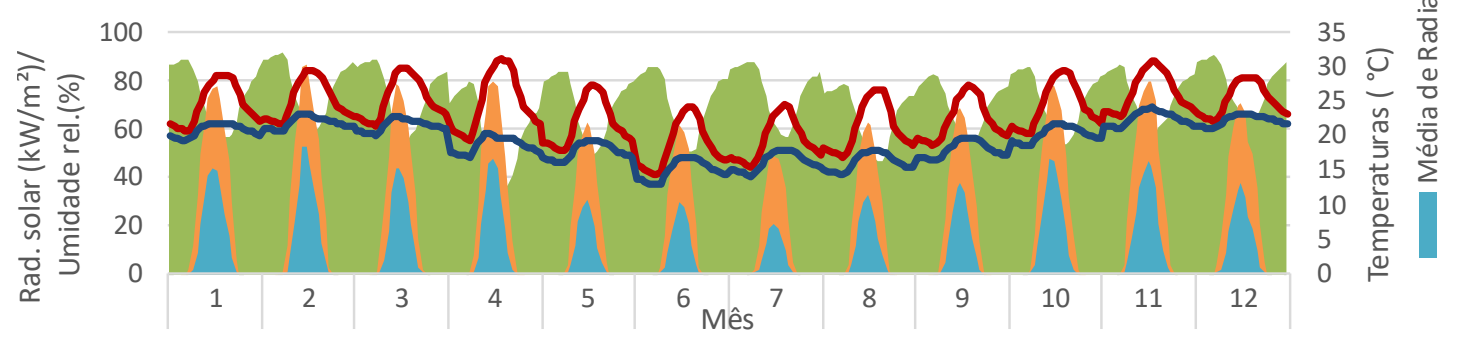

A configuração de ventilação natural foi feita utilizando o módulo AirflowNetwork do programa de simulação. Este módulo calcula o fluxo de ar entre os ambientes e a área externa da edificação, e analisa as aberturas janelas, frestas de janelas e portas internas e externas (PEREIRA et al., 2013). As frações de aberturas para ventilação foram adotadas de acordo com o tipo de janela, com base no Anexo II do RTQ-R (INSTITUTO..., 2012). As frações de abertura para ventilação natural utilizadas neste trabalho estão na Tabela 3. A configuração do coeficiente de descarga e dos coeficientes de pressão do vento foi baseada no Manual de Simulação Computacional de Edifícios Naturalmente Ventilados no Programa EnergyPlus Versão 8.0 (PEREIRA et al., 2013), disponibilizado pelo Centro Brasileiro de Eficiência Energética em Edificações (CENTRO..., 2019). 
Tabela 3 - Fração de abertura para ventilação natural

\begin{tabular}{c|c|c}
\hline Tipo de janela & Imagem & $\begin{array}{c}\text { Fração de abertura para } \\
\text { ventilação natural (\%) }\end{array}$ \\
\hline $\begin{array}{c}\text { Correr com 4 } \\
\text { folhas (2 fixas e 2 } \\
\text { móveis) }\end{array}$ & 40 \\
\hline Basculante & & \\
\hline
\end{tabular}

Fonte: Anexo II do RTQ-R (INSTITUTO..., 2012).

Considerando os dois modelos, percebe-se que o modelo de simulação do desempenho térmico é mais simplificado por gerar menor custo computacional, pois não considera a simulação anual da edificação (para 8.760 horas) ou cargas internas de ocupação e demais equipamentos eletroeletrônicos. Já o modelo de simulação do conforto térmico é mais detalhado, sendo avaliado para o ano inteiro do arquivo climático, considerando a ventilação natural variável ao longo do tempo, além das cargas internas de ocupação, equipamentos e iluminação, configurados de acordo com as recomendações do RTQ-R (INSTITUTO..., 2012).

\section{Variáveis do experimento computacional}

O espaço amostral do experimento deste trabalho compreende todos os resultados de simulação obtidos pela variação de seis variáveis independentes para os dois modelos, apresentadas na Tabela 4. O motivo de analisar todas essas combinações é conhecer o comportamento desse projeto arquitetônico em cenários distintos, especialmente sob diferentes configurações da envoltória. Esse método permite que se observe em mais de um local o comportamento da mesma habitação, configurada com materiais e orientações diferentes.

As demais informações do modelo foram consideradas constantes, tais como o tipo de vidro (simples de 3 $\mathrm{mm}$ ), a ausência de controle solar nas aberturas, os algoritmos de transferência de calor, as propriedades térmicas das portas e o tipo das paredes internas.

Com base nas variáveis independentes da Tabela 4 foram realizadas 1.080 simulações para a avaliação do desempenho térmico e 1.080 simulações para a avaliação do conforto térmico para cada uma das quatro zonas bioclimáticas. No total, 8.640 simulações foram realizadas.

Os valores estabelecidos para a absortância solar, tanto das coberturas quanto das paredes, foram baseados no item 11 da NBR 15575-1 (ABNT, 2013), para as cores clara, média e escura. Os componentes construtivos foram selecionados com base no Anexo Geral V dos Requisitos de Avaliação da Conformidade para a Eficiência Energética de Edificações (RAC), contudo as características térmicas foram calculadas de acordo com a NBR 15220-2 (ABNT, 2005a).

Para abranger uma maior diversidade de sistemas construtivos, foram adotados cinco tipos de paredes (P1 a $\mathrm{P} 5$ ) e seis tipos de coberturas (C1 a C6). Os componentes com camadas com fluxo de calor em paralelo, tais como paredes de blocos furados e coberturas pré-moldadas, foram adaptados para camadas em série de acordo com o método proposto por Ordenes et al. (2003). A Tabela 5 apresenta os tipos de paredes e coberturas adotados com os respectivos valores de transmitância térmica (U) e capacidade térmica (CT).

\section{Análise de desempenho térmico}

Para a análise de desempenho térmico no verão, segundo a NBR 15575-1 (ABNT, 2013), foi adotada a diferença entre a temperatura externa da edificação e a interna do ambiente $\left(T_{e, \text { máx }}-T_{i, m a ́ x}=\Delta T\right)$; para 0 desempenho térmico no inverno foi adotada a diferença entre a temperatura interna do ambiente e a externa da edificação $\left(T_{i, m i ́ n}-T_{e, \text { mín }}=\Delta T\right)$. Dessa maneira, foi padronizado que, quanto maior o valor da diferença de temperatura, maior o desempenho térmico do ambiente. Assim, o desempenho térmico, seja no verão ou no inverno, resultou em um valor positivo. A Tabela 6 apresenta a metodologia adotada para essa avaliação. 
Tabela 4 - Variáveis independentes e seus valores

\begin{tabular}{l|c|c}
\hline \multicolumn{1}{c|}{ Variável } & Unidade & Níveis \\
\hline Absortância solar das coberturas & - & 0,$3 ; 0,5 ; 0,7$ \\
Absortância solar das paredes externas & - & 0,$3 ; 0,5 ; 0,7$ \\
Arquivo climático & - & ZB3; ZB5; ZB6; ZB8 \\
Orientação solar & graus & $0 ; 90 ; 180 ; 270$ \\
Tipos de coberturas & - & C1; C2; C3; C4; C5; C6 \\
Tipos de paredes externas & - & P1; P2; P3; P4; P5 \\
\hline
\end{tabular}

Tabela 5 - Componentes construtivos das paredes externas e coberturas e propriedades térmicas

\begin{tabular}{|c|c|c|c|c|}
\hline Parede & $\begin{array}{l}\text { Anexo } \\
\text { V RAC }\end{array}$ & Descrição & $\begin{array}{c}\mathbf{U} \\
{\left[\mathbf{W} /\left(\mathbf{m}^{2} \mathbf{K}\right)\right]}\end{array}$ & $\begin{array}{c}\mathrm{CT} \\
{\left[\mathbf{k J} / \mathbf{m}^{2} \mathbf{K}\right]} \\
\end{array}$ \\
\hline $\mathrm{P} 1$ & 1 & $\begin{array}{l}\text { - Argamassa interna }(2,5 \mathrm{~cm}) \\
\text { - Bloco de concreto }\left(9 \times 19 \times 39 \mathrm{~cm}^{3}\right) \\
\text { - Argamassa externa }(2,5 \mathrm{~cm})\end{array}$ & 2,78 & 209 \\
\hline $\mathrm{P} 2$ & 21 & - Concreto $(12 \mathrm{~cm})$ & 4,19 & 288 \\
\hline P3 & 22 & $\begin{array}{l}\text { - Tijolo maciço }\left(9 \times 6 \times 19 \mathrm{~cm}^{3}\right) \\
\text { - Argamassa de assentamento }(1,5 \mathrm{~cm})\end{array}$ & 3,65 & 158 \\
\hline $\mathrm{P} 4$ & 34 & $\begin{array}{l}\text { - Placa de gesso }(1,25 \mathrm{~cm}) \\
\text { - Lã de rocha }(9 \mathrm{~cm}) \\
\text { - Placa cimentícia }(1 \mathrm{~cm})\end{array}$ & 0,45 & 33 \\
\hline P5 & 41 & $\begin{array}{l}\text { - Argamassa interna }(2,5 \mathrm{~cm}) \\
\text { - Bloco cerâmico }\left(9 \times 19 \times 19 \mathrm{~cm}^{3}\right) \\
\text { - Argamassa externa }(2,5 \mathrm{~cm})\end{array}$ & 2,39 & 151 \\
\hline C1 & 1 & - Laje maciça $(10 \mathrm{~cm})$ & 3,73 & 220 \\
\hline C2 & 2 & $\begin{array}{l}\text { - Laje pré-moldada } 12 \mathrm{~cm} \text { (concreto } 4 \mathrm{~cm}+\text { lajota } \\
\text { cerâmica } 7 \mathrm{~cm}+\operatorname{argamassa} 1 \mathrm{~cm})\end{array}$ & 2,95 & 167 \\
\hline C3 & 3 & $\begin{array}{l}\text { - Laje pré-moldada } 12 \mathrm{~cm} \text { (concreto } 4 \mathrm{~cm}+\text { EPS } 7 \mathrm{~cm}+ \\
\text { argamassa } 1 \mathrm{~cm} \text { ) }\end{array}$ & 2,29 & 132 \\
\hline $\mathrm{C} 4$ & 4 & $\begin{array}{l}\text { - Laje maciça }(10 \text { cm) } \\
\text { - Câmara de ar (>5 cm) } \\
\text { - Telha cerâmica }\end{array}$ & 2,05 & 238 \\
\hline C5 & 6 & $\begin{array}{l}\text { - Forro PVC }(1 \mathrm{~cm}) \\
\text { - Câmara de ar }(>5 \mathrm{~cm}) \\
\text { - Telha cerâmica }\end{array}$ & 1,75 & 21 \\
\hline C6 & 28 & $\begin{array}{l}\text { - Telhado vegetado extensivo (laje maciça } 10 \mathrm{~cm}+\text { terra } \\
\text { argilosa seca } 10 \mathrm{~cm} \text { + vegetação) }\end{array}$ & 2,18 & 363 \\
\hline
\end{tabular}

Tabela 6 - Critério de avaliação de desempenho térmico NBR 15575-1 (ABNT, 2013)

\begin{tabular}{|c|c|c|c|}
\hline Níveis & Verão (ZB1 ZB7) & Verão (ZB8) & $\begin{array}{c}\text { Inverno (ZB1 a } \\
\text { ZB5) }\end{array}$ \\
\hline Mínimo & \multicolumn{2}{|c|}{$\mathrm{T}_{\mathrm{i}, \text { máx. }} \leq \mathrm{T}_{\mathrm{e}, \text { máx. }}$} & $\mathrm{T}_{\mathrm{i}, \text { mín. }} \geq\left(\mathrm{T}_{\mathrm{e}, \text { mín. }}+3^{\circ} \mathrm{C}\right)$ \\
\hline Intermediário & $\mathrm{T}_{\mathrm{i}, \text { máx. }} \leq\left(\mathrm{T}_{\mathrm{e}, \text { máx. }}-2^{\circ} \mathrm{C}\right)$ & $\mathrm{T}_{\mathrm{i}, \text { máx. }} \leq\left(\mathrm{T}_{\mathrm{e}, \text { máx. }}-1^{\circ} \mathrm{C}\right)$ & $\mathrm{T}_{\mathrm{i}, \text { mín. }} \geq\left(\mathrm{T}_{\mathrm{e}, \text { mín. }}+5^{\circ} \mathrm{C}\right)$ \\
\hline Superior & $\mathrm{T}_{\mathrm{i}, \text { máx. }} \leq\left(\mathrm{T}_{\mathrm{e}, \text { máx. }}-4^{\circ} \mathrm{C}\right)$ & $\mathrm{T}_{\mathrm{i}, \text { máx. }} \leq\left(\mathrm{T}_{\mathrm{e}, \text { máx. }}-2^{\circ} \mathrm{C}\right)$ & $\mathrm{T}_{\mathrm{i}, \text { mín. }} \geq\left(\mathrm{T}_{\mathrm{e}, \text { mín. }}+7^{\circ} \mathrm{C}\right)$ \\
\hline
\end{tabular}

Fonte: adaptada de NBR 15575-1 (ABNT, 2013).

Nota: nas zonas ZB6 a ZB8 nenhum critério de inverno precisa ser verificado. Legenda:

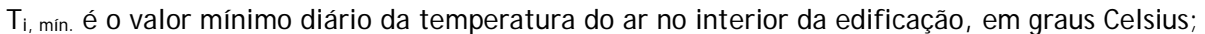

$T_{e}$, mín. é o valor mínimo diário da temperatura do ar exterior à edificação, em graus Celsius;

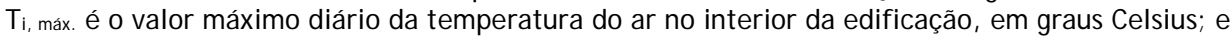

$T_{e}$, máx. é o valor máximo diário da temperatura do ar exterior à edificação, em graus Celsius.

Ressalta-se que a avaliação de desempenho térmico no inverno foi realizada nas Zonas Bioclimáticas 6 e 8 , de forma a possibilitar uma análise mais completa na correlação, embora isso não seja obrigatório de acordo com a NBR 15575-1 (ABNT, 2013). A mesma norma estabelece que a avaliação de desempenho térmico deve 
ser realizada para os ambientes de permanência prolongada da habitação; sendo assim, foram selecionados os dois quartos e a sala para serem investigados.

\section{Análise de conforto térmico}

Entre as metodologias para análise de conforto térmico que podem utilizar simulação computacional, a ASHRAE 55 (AMERICAN..., 2017) prescreve o modelo adaptativo para edificações naturalmente ventiladas, que é o caso das habitações de interesse social. Esse modelo considera a relação da temperatura operativa interna no ambiente com a situação recente da temperatura externa do local. Assim, o modelo computacional da edificação foi configurado de maneira a analisar o conforto térmico dos ocupantes durante as horas ocupadas, considerando as condições de uso previstas no RTQ-R (INSTITUTO..., 2012).

A função utilizada para estabelecer o limite superior para 80\% de aceitabilidade é apresentada na Equação 1, e o limite inferior, na Equação 2. Para a aplicação das funções dos limites de aceitabilidade foi considerada a média de temperatura mensal dos anos de referência dos arquivos climáticos das zonas bioclimáticas adotadas.

$L S=0,31 \times t_{\text {pma(out })}+21,3$

Eq. 1

$L I=0,31 \times t_{\text {pma(out })}+14,3$

Eq. 2

Sendo:

$t_{\text {pma(out) }}$ : temperatura média mensal;

$L S$ : limite de aceitabilidade superior a $80 \%\left({ }^{\circ} \mathrm{C}\right)$; e

$L I$ : limite de aceitabilidade inferior a $80 \%\left({ }^{\circ} \mathrm{C}\right)$.

A Tabela 7 mostra os intervalos de conforto térmico para a temperatura operativa para cada cidade. Os intervalos foram utilizados para o cálculo dos percentuais de horas ocupadas em conforto térmico (POC).

Como indicador de conforto térmico de longo prazo foram utilizadas a porcentagem de horas ocupadas em conforto no calor (POCc) e a porcentagem de horas ocupadas em conforto no frio (POCf). As horas em conforto térmico foram contabilizadas apenas nas horas em que a taxa de ocupação do ambiente era diferente de zero, ou seja, nos momentos em que o ambiente estava efetivamente ocupado. Seguindo essa regra, foram calculadas as porcentagens de desconforto anual para cada ambiente de permanência prolongada em cada simulação realizada.

\section{Tratamento estatístico dos dados}

A análise de correlação foi realizada por meio de gráficos de dispersão entre as variáveis dependentes e também através do coeficiente de correlação de Pearson, calculado com as funções da linguagem de programação R.

Tabela 7 - Intervalos de conforto térmico para a temperatura operativa, com base na ASHRAE Standard 55 (2017)

\begin{tabular}{c|c|c|c|c|c|c|c|c|c|c|c|c}
\hline \multirow{2}{*}{ Mês } & \multicolumn{3}{|c|}{ Ladário } & \multicolumn{3}{c|}{ Coxim } & \multicolumn{3}{c}{ Juti } \\
\cline { 2 - 11 } & TBSm & LI & LS & TBSm & LI & LS & TBSm & LI & LS & TBSm & LI & LS \\
\hline Janeiro & 27,7 & 22,9 & 29,9 & 26,0 & 22,4 & 29,4 & 24,7 & 21,9 & 28,9 & 24,7 & 21,9 & 28,9 \\
Fevereiro & 27,6 & 22,8 & 29,8 & 25,9 & 22,3 & 29,3 & 25,6 & 22,2 & 29,2 & 25,3 & 22,1 & 29,1 \\
Março & 28,1 & 23,0 & 30,0 & 25,7 & 22,3 & 29,3 & 26,0 & 22,4 & 29,4 & 25,4 & 22,2 & 29,2 \\
Abril & 27,6 & 22,9 & 29,9 & 24,6 & 21,9 & 28,9 & 24,6 & 21,9 & 28,9 & 24,9 & 22,0 & 29,0 \\
Maio & 22,2 & 21,2 & 28,2 & 21,4 & 20,9 & 27,9 & 21,4 & 20,9 & 27,9 & 21,9 & 21,1 & 28,1 \\
Junho & 23,1 & 21,4 & 28,4 & 21,4 & 20,9 & 27,9 & 17,0 & 19,6 & 26,6 & 18,7 & 20,1 & 27,1 \\
Julho & 21,9 & 21,1 & 28,1 & 21,5 & 21,0 & 28,0 & 17,6 & 19,8 & 26,8 & 19,4 & 20,3 & 27,3 \\
Agosto & 22,0 & 21,1 & 28,1 & 24,8 & 22,0 & 29,0 & 20,4 & 20,6 & 27,6 & 21,3 & 20,9 & 27,9 \\
Setembro & 28,4 & 23,1 & 30,1 & 25,5 & 22,2 & 29,2 & 21,1 & 20,9 & 27,9 & 22,4 & 21,2 & 28,2 \\
Outubro & 27,0 & 22,7 & 29,7 & 26,6 & 22,6 & 29,6 & 23,8 & 21,7 & 28,7 & 24,5 & 21,9 & 28,9 \\
Novembro & 26,7 & 22,6 & 29,6 & 27,0 & 22,7 & 29,7 & 26,8 & 22,6 & 29,6 & 26,5 & 22,5 & 29,5 \\
Dezembro & 28,8 & 23,2 & 30,2 & 26,2 & 22,4 & 29,4 & 25,7 & 22,3 & 29,3 & 25,3 & 22,2 & 29,2 \\
\hline
\end{tabular}

Nota: TBSm é a temperatura de bulbo seco média mensal do arquivo climático; e LI e LS são os limites inferior e superior de temperatura operativa de conforto térmico respectivamente. 
Foi realizada uma análise de sensibilidade por meio da análise de variância (ANOVA) com o intuito de identificar a influência de cada uma das variáveis independentes no conforto térmico e no desempenho térmico da edificação, conforme o experimento computacional realizado. $\mathrm{O}$ indicador de sensibilidade utilizado foi 0 valor de F. A estatística F (distribuição F) possibilita, por meio de um fator adimensional, verificar a influência de cada variável de entrada nos resultados das simulações. Em linguagem estatística, o valor de F é a razão entre a média dos quadrados de cada termo (variável ou interação) e a média dos quadrados dos resíduos do tratamento. Os 8.640 resultados das simulações foram definidos como a população para a análise estatística e foram analisados com as funções e pacotes da linguagem de programação R.

Para este trabalho a análise de sensibilidade foi feita com as interações de primeira ordem (todas as variáveis independentes individualmente) e de segunda ordem (relacionando a variação do desempenho e do conforto térmico com duas variáveis em conjunto). A Tabela 8 apresenta as variáveis independentes utilizadas para a análise de sensibilidade.

\section{Resultados}

Os resultados são apresentados e discutidos nesta seção, inicialmente a análise de sensibilidade das variáveis independentes sobre os resultados de desempenho térmico e das variáveis independentes sobre os resultados de conforto térmico. Após essas análises, são apresentadas as correlações entre conforto e desempenho térmico.

\section{Análise de sensibilidade no desempenho térmico}

A Figura 3, dividida em (a) verão e (b) inverno, apresenta as cinco variáveis independentes que mais influenciaram no desempenho térmico de cada um dos casos. A medida de sensibilidade é representada pelo valor-F.

É possível observar que as variáveis absortância da cobertura (AbCob), absortância das paredes (AbPar), variação do componente construtivo das coberturas (VarCob) e variação do componente construtivo das paredes externas (VarPar) foram as que apareceram entre as cinco mais influentes para todos os casos. A variável AbCob foi a que mais influenciou no desempenho térmico no verão em todas as situações, seguida de AbPar e VarCob. No desempenho térmico no inverno a variável VarCob foi a que mais influenciou nos resultados, seguida de VarPar, AbCob e AbPar.

Para visualizar melhor a variação dos resultados de desempenho térmico ante as variáveis mais influentes, a Figura 4 apresenta os resultados para as cidades de Ladário, no verão, e Juti, no inverno, por serem respectivamente as cidades mais quente e mais fria deste estudo. No caso do desempenho térmico no verão as variáveis destacadas foram AbCob e AbPar; já para o inverno foram VarCob e AbCob.

Tabela 8 - Variáveis independentes para a ANOVA

\begin{tabular}{c|l}
\hline Variável & \multicolumn{1}{c}{ Significado } \\
\hline AbCob & Variação da absortância da cobertura \\
AbPar & Variação da absortância das paredes \\
AP:AC & Interação entre AbPar e AbCob \\
Ori & Variação da orientação solar da edificação \\
Ori:AC & Interação entre Ori e AbCob \\
Ori:AP & Interação entre Ori e AbPar \\
VarCob & Variação do componente construtivo das coberturas \\
VC:AC & Interação entre VarCob e AbCob \\
VC:AP & Interação entre VarCob e AbPar \\
VC:Ori & Interação entre VarCob e Ori \\
VC:VP & Interação entre VarCob e VarPar \\
VarPar & Variação do componente construtivo das paredes externas \\
VP:AC & Interação entre VarPar e AbCob \\
VP:AP & Interação entre VarPar e AbPar \\
VP:Ori & Interação entre VarPar e Ori \\
\hline
\end{tabular}


Figura 3 - Análise de sensibilidade das variáveis independentes para o desempenho térmico

\begin{tabular}{|c|c|c|c|c|c|c|c|c|c|c|c|}
\hline \multicolumn{6}{|c|}{ (a) Verão } & \multicolumn{6}{|c|}{ (b) Inverno } \\
\hline & & \multicolumn{4}{|c|}{ Valor-F } & & & \multicolumn{4}{|c|}{ Valor-F } \\
\hline Amb & Variável & Ladário & Coxim & Juti & Sidrol. & Amb & Variável & \begin{tabular}{|l|} 
Ladário \\
\end{tabular} & Coxim & Juti & Sidrol. \\
\hline \multirow{6}{*}{ 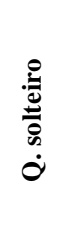 } & AbCob & 162.715 & 127.552 & 165.446 & 144.887 & \multirow{6}{*}{ 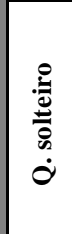 } & \multirow{3}{*}{$\begin{array}{l}\text { AbCob } \\
\text { AbPar } \\
\text { VarCob }\end{array}$} & 11.784 & 185.257 & 216.805 & 166.909 \\
\hline & AbPar & 62.110 & 62.447 & 63.589 & $\$ 8.166$ & & & $\square \quad 5.919$ & $\square 81.673$ & 100.209 & 84.660 \\
\hline & Ori & & 4.638 & & & & & 34.592 & 337.531 & 274.292 & 567.010 \\
\hline & VarCob & 43.472 & $\$ 0.499$ & 43.095 & 35.730 & & VC:AP & & & & 3.554 \\
\hline & VarPar & $\square \quad 21.474$ & 24.788 & 17.448 & 15.635 & & VarPar & 27.586 & 162.872 & 148.028 & 532.614 \\
\hline & VP:AP & 2.757 & & 2.763 & 2.578 & & VP:AP & 235 & 3.295 & 4.159 & \\
\hline \multirow{7}{*}{$\begin{array}{l}\bar{\nabla} \\
\tilde{y} \\
\dot{\sigma}\end{array}$} & AbCob & 150.627 & 124.433 & 154.228 & 136.752 & \multirow{7}{*}{$\begin{array}{l}\overline{\widetilde{J}} \\
\tilde{J} \\
\dot{\sigma}\end{array}$} & \multirow{7}{*}{$\begin{array}{l}\text { AbCob } \\
\text { AbPar } \\
\text { VarCob } \\
\text { VC:AC } \\
\text { VC:VP } \\
\text { VarPar } \\
\text { VP:AP }\end{array}$} & 12.329 & 182.603 & 219.939 & 168.027 \\
\hline & AbPar & 55.729 & 59.363 & 57.473 & $\$ 3.104$ & & & 6.274 & 81.477 & 102.316 & 86.305 \\
\hline & Ori & & 4.149 & & & & & 37.352 & 341.018 & 285.713 & 586.662 \\
\hline & VarCob & 40.743 & 50.588 & 40.835 & 34.237 & & & & & 4.269 & \\
\hline & VarPar & 18.829 & 23.200 & 15.508 & 14.007 & & & & & & 3.577 \\
\hline & VP:AP & 2.468 & & 2.496 & 2.355 & & & 28.364 & 156.045 & 145.561 & 524.912 \\
\hline & & & & & & & & 250 & 3.306 & & \\
\hline \multirow{6}{*}{$\frac{\pi}{\tilde{n}}$} & AbCob & 172.224 & 163.402 & 196.359 & 185.341 & \multirow{6}{*}{$\frac{\pi}{\pi}$} & \multirow[b]{6}{*}{ VarPar } & 12.859 & $1 \$ 6.287$ & 231. 938 & \rceil 148.849 \\
\hline & AbPar & 51.108 & 64.435 & 57.873 & 56.524 & & & 5.610 & $\square \quad 60.452$ & 90.461 & 63.643 \\
\hline & Ori & ] 16.853 & $\square \quad 29.445$ & 17.747 & 19.392 & & & 302 & & & 3.622 \\
\hline & VarCob & 59.210 & 93.257 & ] 67.048 & ] 60.011 & & & 53.296 & 402.345 & 412.509 & 676.870 \\
\hline & \multirow[t]{2}{*}{ VarPar } & 12.798 & $\square \quad 24.645$ & 14.082 & 12.318 & & & & 2.997 & 5.473 & \\
\hline & & & & & & & & 21.215 & 92.938 & 104.447 & 313.399 \\
\hline & -Variação d & ortância da c & $\begin{array}{l}\text { eertura } \\
\text { rededes }\end{array}$ & & & \multicolumn{6}{|c|}{$\begin{array}{l}\text { VC:AC-Interação entre VarCob e AbCob } \\
\text { VC:AP-Interação entre VarCob e AbPar } \\
\text { VC:VP-Interação entre VarCob e VarPar } \\
\text { VP:AP-Interação entre VarPar e AbPar }\end{array}$} \\
\hline
\end{tabular}

Figura 4 - Análise de variação do desempenho térmico de acordo com as duas variáveis mais influentes: (a) Ladário e (b) J uti

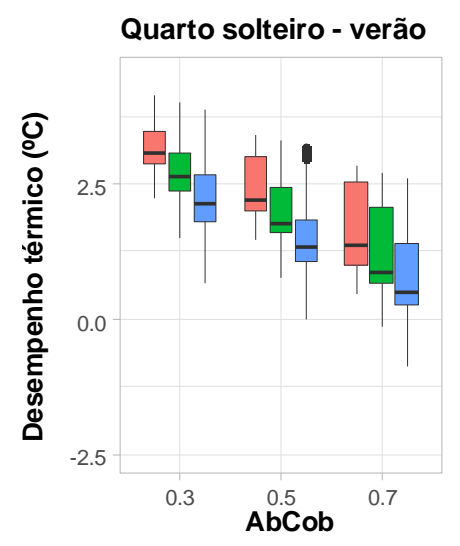

Quarto solteiro - inverno

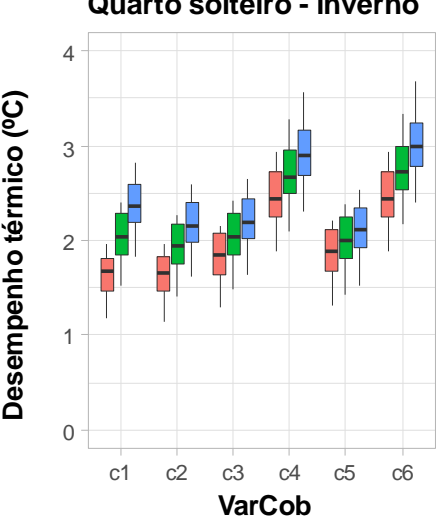

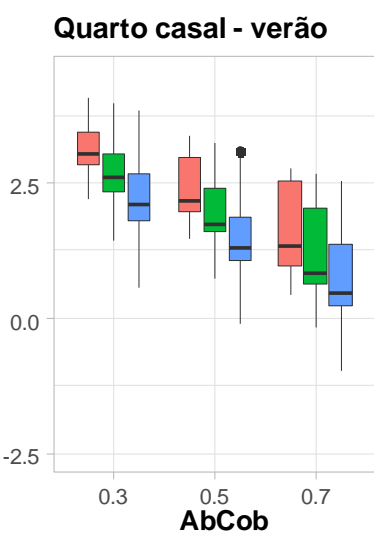

Quarto casal - inverno

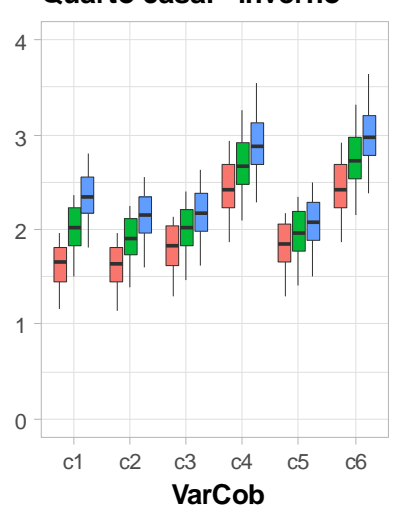

Sala - verão

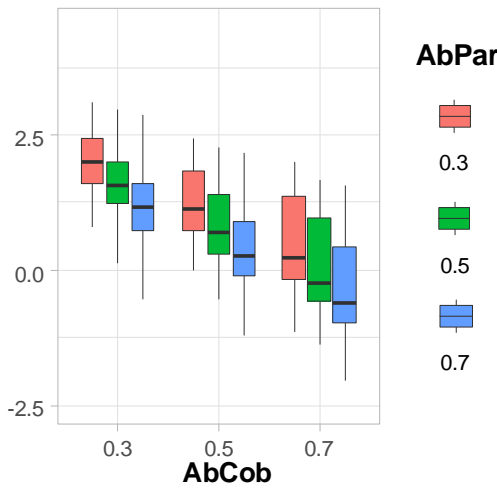

Sala - inverno

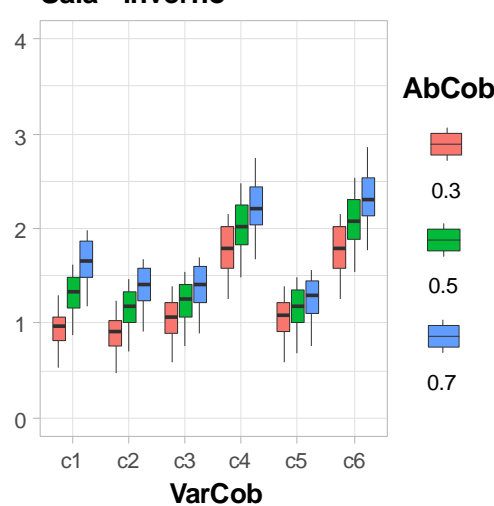


Com base na Figura 4 é possível observar que, no caso do verão, a absortância solar da cobertura (AbCob) notoriamente separa os resultados em grupos distintos de desempenho térmico, assim como a absortância solar das paredes (AbPar), sendo o melhor desempenho, em todas as situações, para os valores mais baixos dessas variáveis. No caso do inverno também é nítida a variação devido à absortância da cobertura, porém, como já citado anteriormente, de forma inversa ao desempenho no verão. Entre os níveis da variável VarCob (tipo de cobertura) percebe-se um comportamento similar no inverno nas coberturas C4 (laje maciça, com câmara de ar e telha) e C6 (cobertura verde), apesar da diferença na capacidade térmica desta última. Assim, os melhores desempenhos foram obtidos no caso da cobertura de maior capacidade térmica e maior absortância solar (no inverno) para Juti.

\section{Análise de sensibilidade da variável dependente conforto térmico}

A Figura 5 mostra as cinco variáveis independentes que mais influenciaram o conforto térmico de cada um dos casos, cuja medida de sensibilidade é o valor-F.

As variáveis independentes AbCob, AbPar, VarCob e VarPar apareceram entre as cinco mais influentes no conforto térmico em praticamente todos os casos, exceto no conforto térmico no calor em Juti no quarto de solteiro e no quarto de casal.

A AbCob foi a variável independente com maior influência no conforto térmico no calor, seguida por AbPar e VarCob. No caso de conforto térmico no frio, as variáveis VarPar, AbCob e VarCob, consecutivamente, foram as que mais interagiram com a variação dos resultados.

A incerteza proporcionada pela variável absortância solar da cobertura, no caso do calor, e a variação de tipos de componentes das paredes externas no frio corroboram os resultados obtidos por Silva, Almeida e Ghisi (2017), em que retratam a influência da absortância solar dos materiais da cobertura no conforto térmico em situações de calor. No caso de conforto térmico no frio, os autores ressaltam a influência dos tipos de componentes das paredes.

A Figura 6 apresenta a variação do conforto térmico com relação às variáveis AbCob e AbPar no verão para a cidade de Ladário, e no inverno para a cidade de Juti.

Assim como no caso do desempenho térmico, a absortância solar da cobertura (AbCob) deixa clara sua influência na variação do conforto térmico dos ambientes nesta situação, tanto tens algo mais à venda? quanto no frio.

Figura 5 - Análise de sensibilidade das variáveis independentes para o conforto térmico

(a) Calor

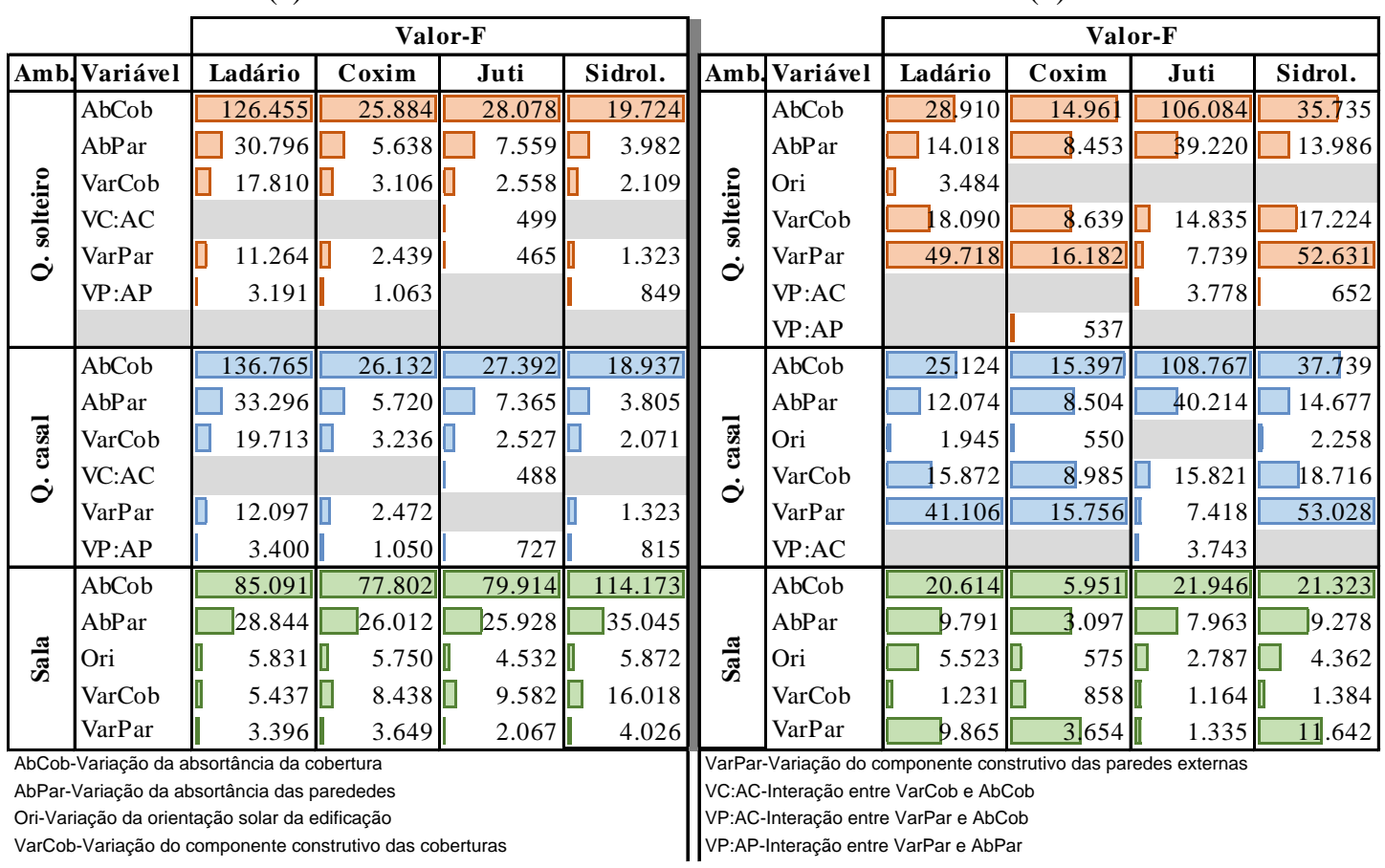


Destaca-se que as variáveis que possuem maior influência nos resultados de conforto térmico e desempenho térmico são praticamente as mesmas. Certamente a diferença que existe é devida ao fato de que o desempenho térmico é calculado de acordo com a maior temperatura interna durante o dia, que ocorre no horário vespertino; e no caso da análise de conforto térmico o desempenho está relacionado com a ocupação de cada ambiente, que na maior parte dos casos ocorre em horário noturno nos quartos.

\section{Análise de correlação entre conforto e desempenho térmico}

Para melhor visualização dos resultados são apresentados os gráficos de dispersão relacionando o desempenho e o conforto térmico dos ambientes de permanência prolongada. Os resultados foram divididos por cidade, separando o desempenho no verão (calor) e no inverno (frio). Além da análise de correlação, foi destacada a variação dos resultados de acordo com a absortância solar da cobertura (AbCob), para se poder identificar esse agrupamento por uma das variáveis mais influentes.

Os gráficos de dispersão da cidade de Ladário são apresentados na Figura 7. Observa-se que para essa cidade a maior parte dos resultados atendeu ao desempenho mínimo no verão e é possível se atingir até mesmo o nível superior para os ambientes, mesmo sendo a zona bioclimática mais quente deste estudo. É importante ressaltar que o conforto térmico não obteve o melhor desempenho possível na condição de calor para a sala, pois para todos os casos os resultados estão abaixo de 70\% de POCc.

Ao se analisar o desempenho térmico da sala no verão e o desempenho térmico dos quartos no inverno, podese constatar que a "nuvem" de pontos tende a uma ascensão, retratando que, quando se melhora o desempenho térmico, o conforto térmico também aumenta. Nos outros casos a ascensão da nuvem de pontos também acontece, só que com grupos de concentração mais dispersos. Esse comportamento retrata uma possível correlação entre conforto e desempenho térmico para essa zona bioclimática (ZB 8).

Figura 6 - Análise de variação do conforto térmico de acordo com as duas variáveis mais influentes: (a) Ladário e (b) J uti

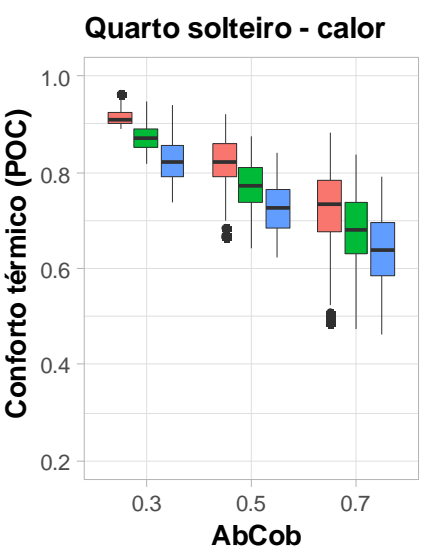

Quarto solteiro - frio

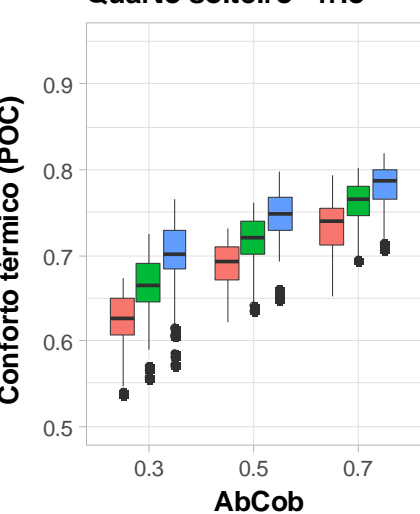

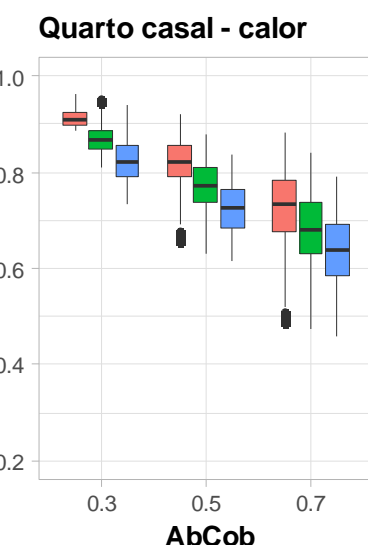

Quarto casal - frio

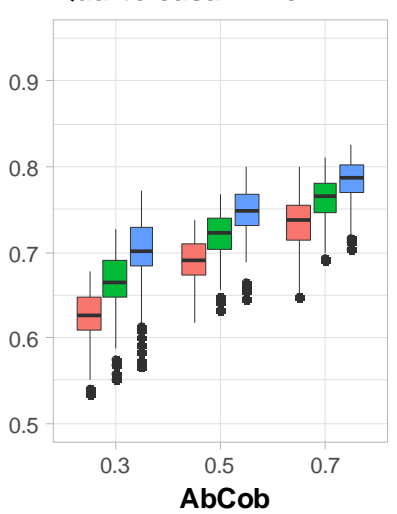

Sala - calor

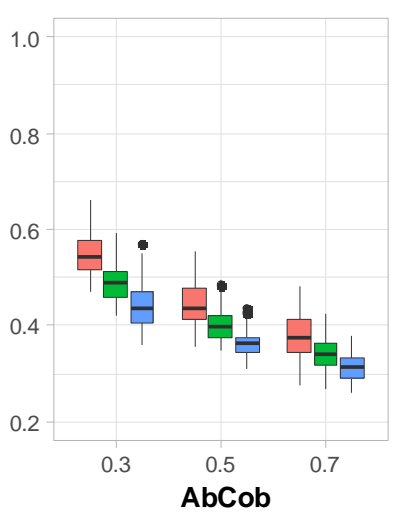

AbPar

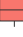

0.3

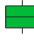

0.5

$\square$

0.7

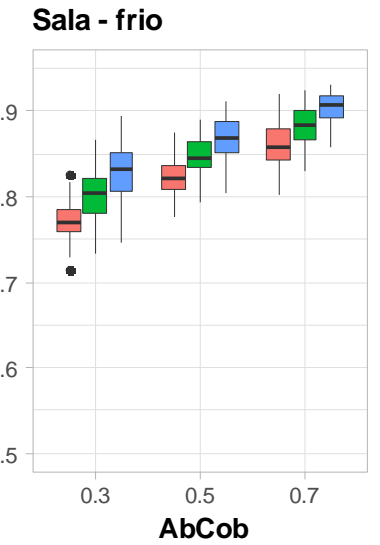

AbPar 


\section{Figura 7 - Correlação entre desempenho e conforto térmico para a cidade de Ladário (ZB8)}
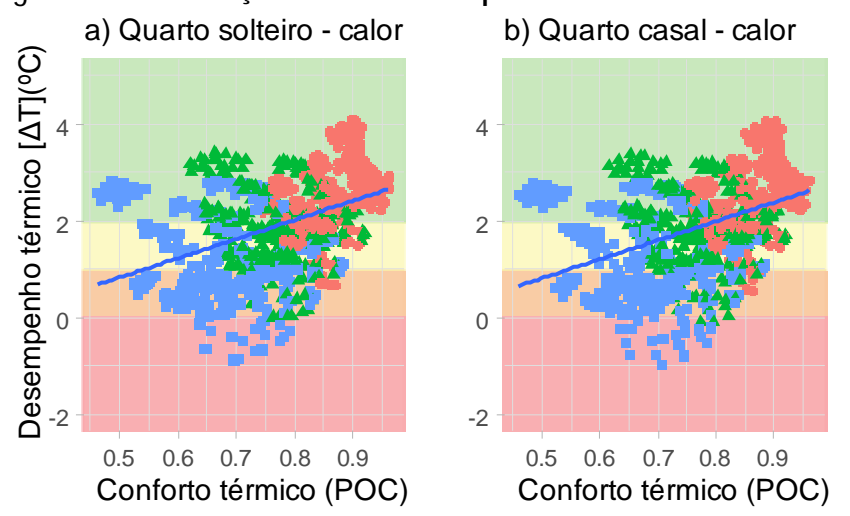

d) Quarto solteiro - frio

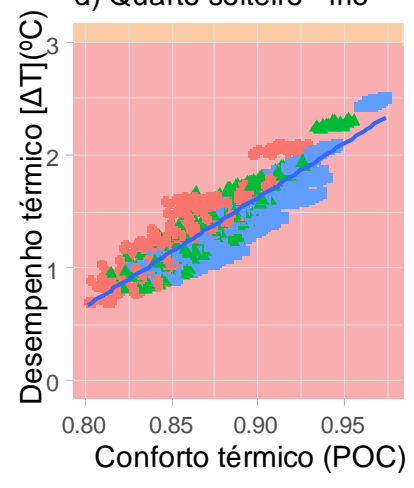

e) Quarto casal - frio

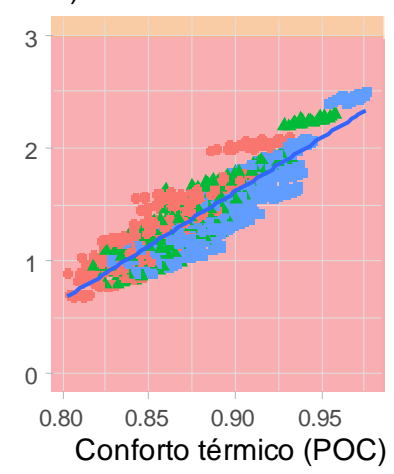

c) Sala - calor

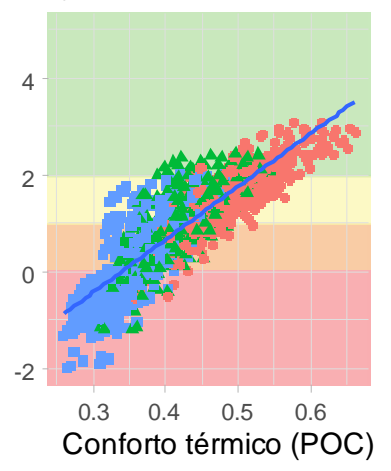

Variação

AbCob:

0.3

$\Delta \quad 0.5$

0.7

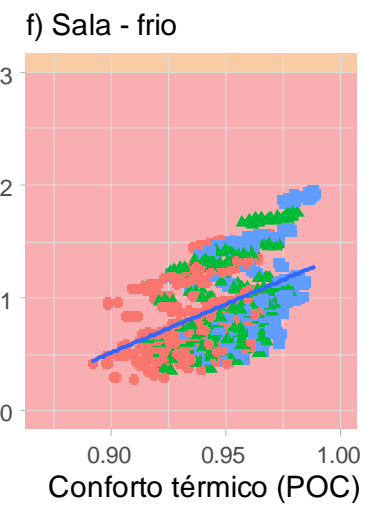

Classificação NBR 15575-1:

- Superior

Intermediário

Mínimo

Não atende

Pode-se observar que em Ladário (Figura 7) a variável AbCob influencia diretamente o conforto térmico no calor (POCc). Os pontos com maior nível de conforto são os com AbCob igual a 0,3, e os menores são os pontos com AbCob igual a 0,7. Isso não ocorre tão notadamente no desempenho térmico no verão. Há pontos com AbCob igual a 0,7 dentro da faixa de "nível superior" de desempenho, i.e., com $\Delta T$ maior do que $2{ }^{\circ} \mathrm{C}$ (nos quartos).

Os gráficos de dispersão da cidade de Coxim são apresentados na Figura 8. O comportamento da nuvem de pontos para esse caso se assemelha ao ocorrido para a cidade de Ladário, o que demonstra a mesma correlação entre os eixos. Porém, a concentração de pontos é mais intensa no desempenho térmico no verão da sala e no inverno dos quartos, e o desempenho no inverno na sala resultou em grupos de concentração de pontos menos dispersos, quando comparado com todas as outras zonas bioclimáticas.

No caso da cidade de Coxim, mais especificamente na análise de verão, todos os resultados atingiram ao menos o nível mínimo, mesmo com situações em que o conforto no ambiente está próximo a 20\% das horas ocupadas, como na sala. Essa comparação pode mostrar que a avaliação de conforto térmico é mais rigorosa, enquanto o desempenho térmico acaba considerando que é uma situação satisfatória.

Os gráficos de dispersão de Juti são apresentados na Figura 9. É importante frisar que esta cidade está localizada na zona bioclimática mais fria do estado (ZB 3) e, mesmo assim, os resultados demonstraram que, entre todas as cidades analisadas, esta apresentou melhor desempenho térmico no frio. Esse comportamento pode ser procedente da variável velocidade do vento (Tabela 2), que para esse dia típico foi igual a zero, acarretando menores perdas de calor por convecção. Observa-se ainda que poucos resultados atingiram o desempenho térmico mínimo para verão e para inverno. Mesmo assim, na análise de correlação é possível observar uma interação entre o conforto e o desempenho térmico dos ambientes.

Ao contrário da cidade de Coxim, em Juti percebe-se, na análise de verão, que grande parte dos resultados de conforto térmico foram superiores a $70 \%$ das horas ocupadas; contudo, a maior parte dos resultados de desempenho térmico não atendeu sequer ao nível mínimo. Esse comportamento demonstra que o método da NBR 15575-1 (ABNT, 2013) pode falhar em algumas situações no quesito conforto térmico do usuário da habitação. 
Figura 8 - Correlação entre desempenho e conforto para a cidade de Coxim (ZB6)
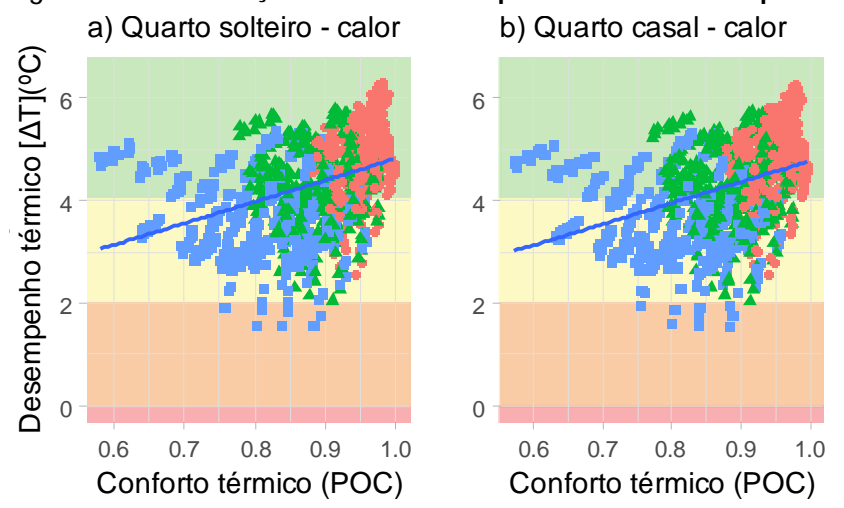

c) Sala - calor

d) Quarto solteiro - frio

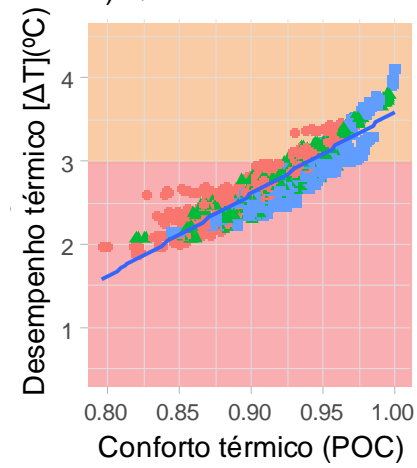

e) Quarto casal - frio
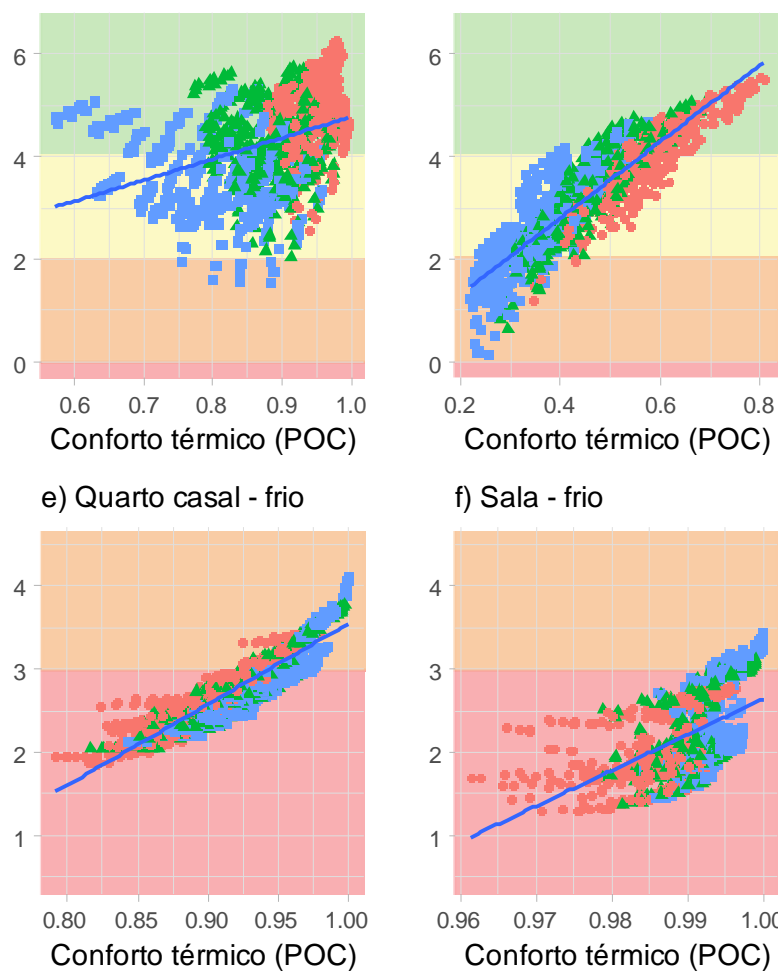

Variação

AbCob:

0.3

$\Delta \quad 0.5$

0.7

Conforto térmico (POC)

Classificação

f) Sala - frio

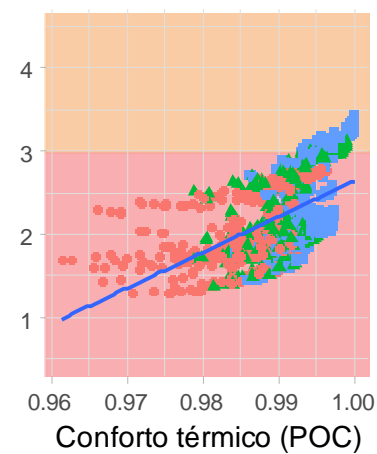

NBR 15575-1:

- Superior

Intermediário

Mínimo

- Não atende

Figura 9 - Correlação desempenho e conforto para a cidade de J uti (ZB3)
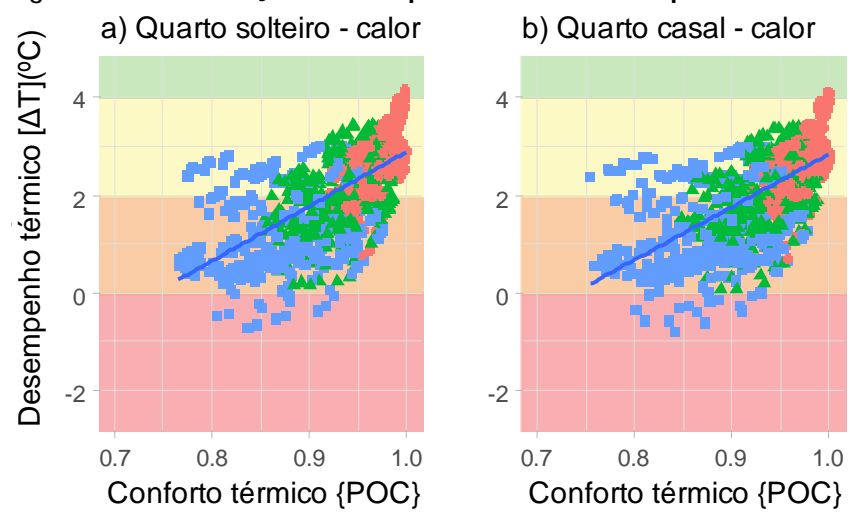

c) Sala - calor

d) Quarto solteiro - frio

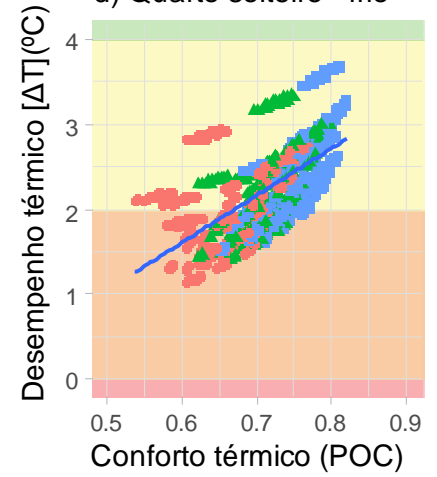

e) Quarto casal - frio
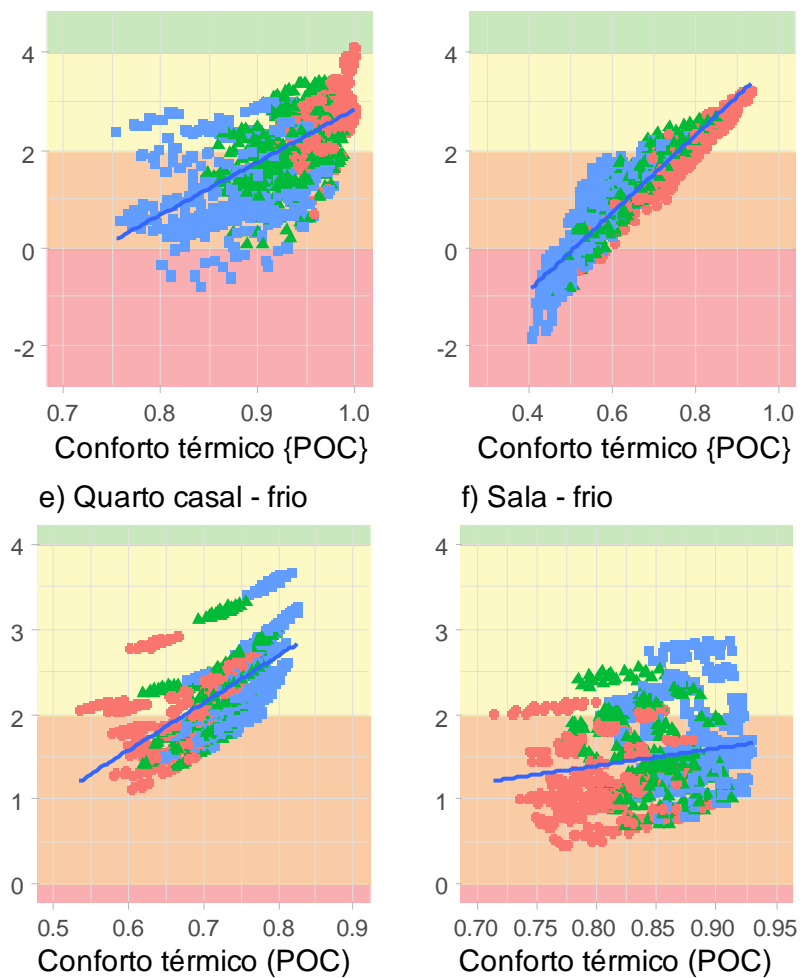

Variação

AbCob:

0.3

- 0.5

0.7

f) Sala - frio

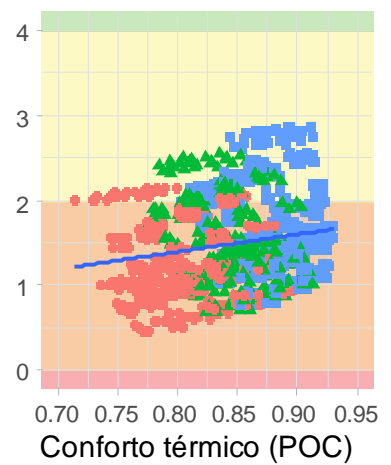

Classificação NBR 15575-1:

- Superior

Intermediário

- Mínimo

Não atende 
Figura 10 - Correlação entre desempenho e conforto para a cidade de Sidrolândia (ZB5)
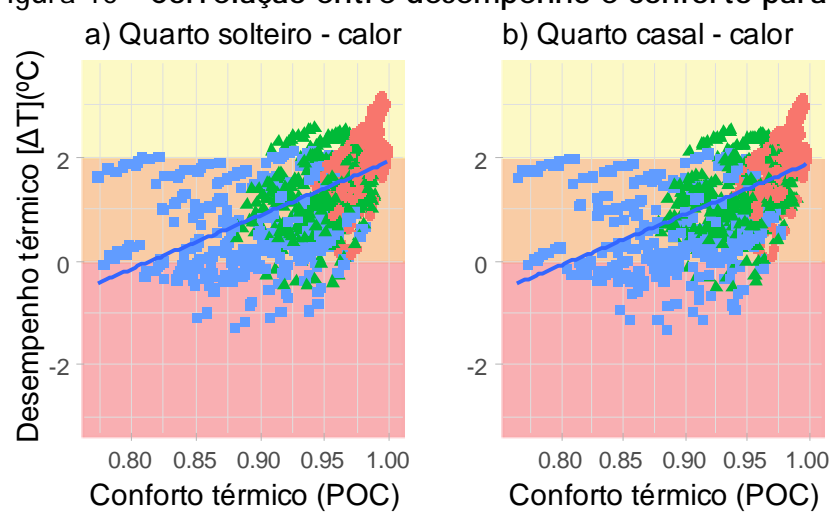

c) Sala - calor

d) Quarto solteiro - frio

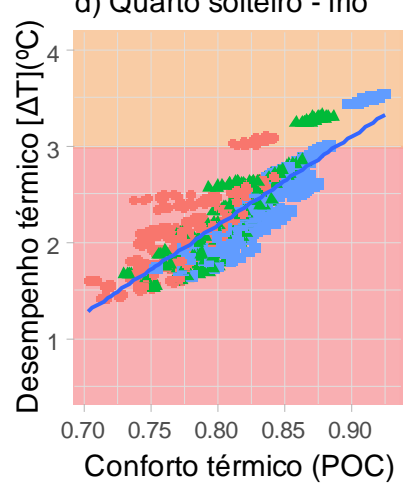

e) Quarto casal - frio
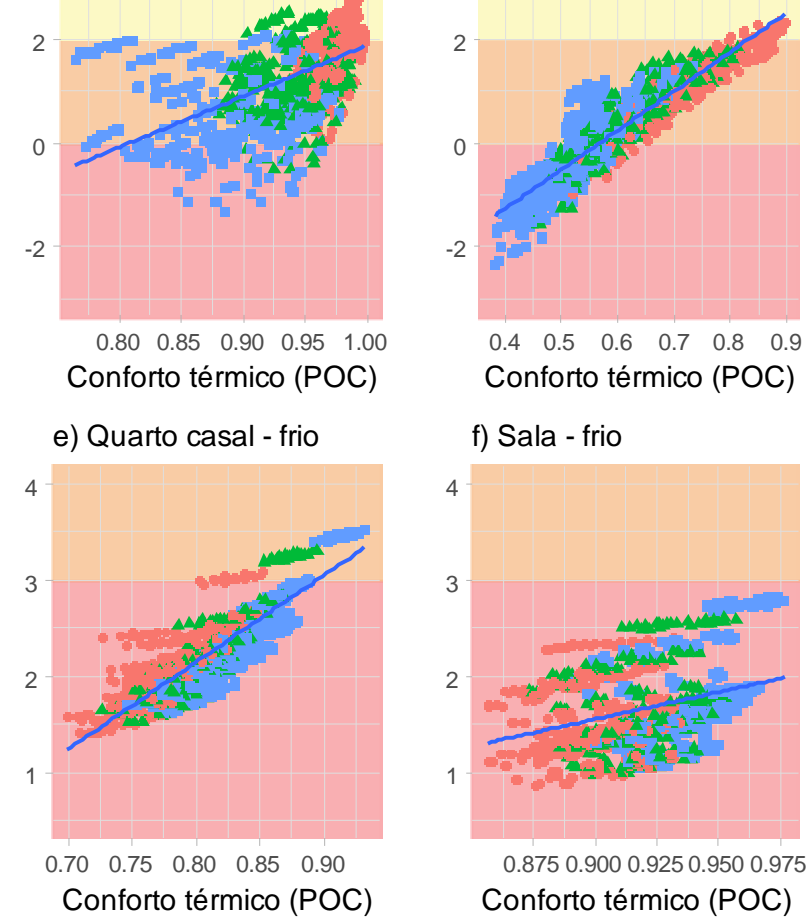

Variação

AbCob:

0.3

$\Delta .5$

0.7

f) Sala - frio

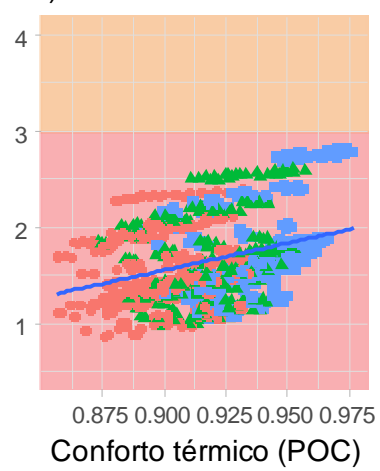

Classificação NBR 15575-1:

- Superior

Intermediário

Mínimo

Não atende

Os resultados para a cidade de Sidrolândia são apresentados na Figura 10. Estes se comportaram de forma semelhante aos resultados obtidos para a cidade de Juti.

Para todos os casos há certo nível de correlação entre conforto e desempenho térmico, porém a variação dos resultados não segue de forma simétrica ou com as mesmas taxas de variação. É notável também a influência da variável AbCob nos resultados, pois, com maior valor de absortância (0,7), menor é o valor do critério no verão (calor) e maior é o valor do critério no inverno (frio), seja no desempenho térmico ou no conforto térmico.

A Tabela 9 mostra os coeficientes de correlação entre a variável dependente de percentual de horas ocupadas em conforto térmico com a diferença de temperatura (desempenho térmico) para cada ambiente em cada um dos climas. O coeficiente de Pearson chegou a um valor máximo de 0,938 em Juti para o ambiente da sala na condição de calor (verão). O menor valor foi obtido também em Juti para a sala na condição de frio (inverno), de 0,186. Esses coeficientes corroboram o aspecto visual das Figuras 7 a 10.

Em uma análise geral dos resultados, todos os gráficos dos quartos, no verão, tiveram comportamento semelhante. Nesses casos há dispersão maior nos pontos, o que pode ser justificado pela diferença dos métodos de simulação. O método da NBR 15575-1 (ABNT, 2013) considera apenas a maior temperatura atingida no dia, a qual ocorre no período da tarde; no caso da análise de conforto térmico a verificação é feita no horário em que o usuário está no quarto, o que ocorre no período noturno. O caso das salas é uma situação distinta, em que há ocupação no período da tarde, no momento de pico de temperatura interna.

No inverno o comportamento é diferente; os gráficos demonstram maior concentração dos pontos, no caso dos quartos, o que corrobora a afirmação anterior. No método da norma, a menor temperatura ocorre no período noturno, assim como a ocupação dos quartos, no caso da análise de conforto térmico.

\section{Conclusões}

Este trabalho analisou a eficácia do método de simulação da NBR 15575-1 (ABNT, 2013) para a avaliação do desempenho térmico diante do conforto térmico dos ocupantes. Esta investigação foi possível devido às análises de correlação entre desempenho e conforto térmico, e também à análise de variância realizada, e constatou-se interação entre esses dois critérios de desempenho. 
Tabela 9 - Coeficientes de correlação de Pearson entre conforto e desempenho térmico para cada ambiente em cada clima

\begin{tabular}{c|c|c|c|c|c}
\hline \multirow{2}{*}{ Ambiente } & \multirow{2}{*}{ Variável $\{\mathbf{x} \times \mathbf{y}\}$} & \multicolumn{4}{|c}{ Coeficiente de Pearson } \\
\cline { 3 - 6 } & & Ladário & Coxim & Juti & Sidrolândia \\
\hline Quarto solteiro & POCc $\times \Delta \mathrm{T}$ (verão) & 0,427 & 0,380 & 0,635 & 0,551 \\
Quarto casal & POCc $\times \Delta \mathrm{T}$ (verão) & 0,421 & 0,375 & 0,628 & 0,541 \\
Sala & POCc $\times \Delta \mathrm{T}$ (verão) & 0,856 & 0,894 & 0,938 & 0,931 \\
Quarto solteiro & POCf $\times \Delta \mathrm{T}$ (inverno) & 0,895 & 0,905 & 0,624 & 0,828 \\
Quarto casal & POCf $\times \Delta \mathrm{T}$ (inverno) & 0,895 & 0,901 & 0,631 & 0,825 \\
Sala & POCf $\times \Delta \mathrm{T}$ (inverno) & 0,469 & 0,566 & 0,186 & 0,320 \\
\hline
\end{tabular}

Nos casos da avaliação do desempenho e conforto térmico no frio é possível observar essa relação de forma mais evidente, pois na maior parte dos casos o conforto térmico é maior quanto maior o desempenho térmico dos ambientes. Para os casos de desempenho térmico no calor há um comportamento um pouco diferente, pois é notório que há ascensão na "nuvem” de pontos, o que demonstra que, ao aumentar o desempenho térmico, o conforto dos usuários também aumenta; porém, a correlação é menos proporcional do que no caso do desempenho no frio, pois há uma dispersão maior dessa nuvem de pontos.

Essa maior dispersão pode ser justificada pelo fato de que, para a análise de desempenho térmico, a temperatura utilizada para tal é atingida no período da tarde. No caso da análise de conforto, mesmo que a maior temperatura ocorra de tarde, a análise é feita apenas no horário em que o usuário se encontra no ambiente, retratando a importância de se considerar a ocupação mais provável do ambiente em uma avaliação.

Por meio da análise de sensibilidade, constatou-se que a absortância solar das paredes e coberturas (AbPar e AbCob) e os tipos de cobertura e parede (VarCob e VarPar) são as variáveis independentes que mais influenciam nos resultados, tanto de desempenho quanto de conforto térmico. Essa influência pode estar relacionada diretamente com a correlação existente entre desempenho e conforto térmico.

Os resultados mostraram casos em que o ambiente pode possuir bom desempenho térmico (conforme o método atual da NBR 15575-1 (ABNT, 2013)) e mesmo assim proporcionar baixos níveis de conforto térmico ao usuário (próximo de $20 \%$ de horas ocupadas em conforto). Ocorre também o inverso em alguns casos: haver bom conforto térmico, mas não bom desempenho térmico conforme a norma. Esse cenário reitera a importância da análise de conforto térmico diante do desempenho térmico, pois esse aspecto não é levado em consideração pela NBR 15575-1 (ABNT, 2013). Assim, pelo fato da análise ser feita apenas por diferença de temperatura do ar interna e externa dos ambientes, muitas informações acerca do conforto térmico que o ambiente proporcionaria são indeterminadas.

Neste momento de revisão da norma, este trabalho contribui com uma análise mais ampla sobre a necessidade de aplicação de índices de conforto térmico no ambiente, tendo apresentado a correlação entre os índices avaliados (desempenho/conforto). O trabalho reitera também a importância de se conhecer a utilização da habitação, com taxas de ocupação mais próximas das condições reais dos ambientes.

Este trabalho limitou-se a analisar somente um tipo de projeto arquitetônico de habitação de interesse social unifamiliar, além de considerar uma quantidade reduzida de variáveis de entrada para viabilizar uma análise fatorial da amostra, dada a disponibilidade limitada de computadores para a realização das simulações. É recomendado que trabalhos futuros possam fazer uma análise de uma amostra maior, oriunda de tipologias de projetos diversificadas e com a análise de mais variáveis independentes, utilizando computadores com maior capacidade de processamento.

\section{Referências}

AMERICAN SOCIETY OF HEATING, REFRIGERATING AND AIR-CONDITIONING ENGINEERS. Standard 55: thermal environmental conditions for human occupancy. Atlanta, 2017.

ASSOCIAÇÃO BRASILEIRA DE NORMAS TÉCNICAS. NBR 15220-2: Desempenho térmico de edificações: Métodos de cálculo da transmitância, da capacidade térmica, do atraso térmico e do fator solar de elementos e componentes de edificações. Rio de Janeiro, 2005a.

ASSOCIAÇÃO BRASILEIRA DE NORMAS TÉCNICAS. NBR 15220-3: Desempenho térmico de edificações: Zoneamento bioclimático brasileiro e diretrizes construtivas para habitações unifamiliares de interesse social. Rio de Janeiro, 2005b. 
ASSOCIAÇÃO BRASILEIRA DE NORMAS TÉCNICAS. NBR 15575-1: edificações habitacionais: desempenho: requisitos gerais. Rio de Janeiro, 2013.

BRE, F. et al. Residential building design optimisation using sensitivity analysis and genetic algorithm. Energy and Buildings, v. 133, p. 853-866, 2016.

CAPOZZOLI, A.; GORRINO, A.; CORRADO, V. A building thermal bridges sensitivity analysis. Applied Energy, v. 107, p. 229-243, 2013.

CENTRO BRASILEIRO DE EFICIÊNCIA ENERGÉTICA EM EDIFICAÇÕES. Manual de simulação computacional de edifícios naturalmente ventilados no programa EnergyPlus Versão 8.0. Disponível em: http://cb3e.ufsc.br/sites/default/files/Manual_Ventilacao_v8.0.pdf. Acesso em: 27 maio 2019.

CHVATAL, K. M. S. Avaliação do procedimento simplificado da NBR 15575 para determinação do nível de desempenho térmico de habitações. Ambiente Construído, Porto Alegre, v. 14, n. 4, p. 119-134, out./dez. 2014.

FRONTCZAK, M.; WARGOCKI, P. Literature survey on how different factors influence human comfort in indoor environments. Building and Environment, v. 46, n. 4, p. 922-937, 2011.

GIVONI, B. Comfort, climate analysis and building design guidelines. Energy and Buildings, v. 18, p. 1123, 1992.

GOULART, S. V. G.; LAMBERTS, R.; FIRMINO, S. Dados climáticos de 14 cidades brasileiras. São Paulo: Abrava, 1998.

INSTITUTO NACIONAL DE METROLOGIA, QUALIDADE E TECNOLOGIA. Portaria no 18, de 16 de janeiro de 2012. Regulamento Técnico da Qualidade para a Eficiência Energética de Edificações Residenciais (RTQ-R). Rio de Janeiro, 2012.

LAM, T. C.; GE, H.; FAZIO, P. Energy positive curtain wall configurations for a cold climate using the Analysis of Variance (ANOVA) approach. Building Simulation, v. 9, n. 3, p. 297-310, 2016.

MAZZEFERRO, L.; MELO, A. P.; LAMBERTS, R. Manual de simulação computacional de edifícios com o uso do objeto ground domain no programa Energyplus. Florianópolis: Laboratório de Eficiência Energética de Edificações do Departamento de Engenharia Civil da UFSC, 2015.

MECHRI, H. E.; CAPOZZOLI, A.; CORRADO, V. Use of the ANOVA approach for sensitive building energy design. Applied Energy, v. 87, n. 10, p. 3073-3083, 2010.

MORENO, A. C. R.; MORAIS, I. S.; SOUZA, R. G. Thermal performance of social housing-a study based on Brazilian regulations. In: INTERNATIONAL CONFERENCE ON SUSTAINABILITY IN ENERGY AND BUILDINGS, 8., Turin, 2016. Proceedings [...] Turin: Elsiever Procedia, 2017.

OLIVEIRA, R. D. et al. Thermal comfort for users according to the Brazilian housing buildings performance standards. In: INTERNATIONAL CONFERENCE ON SUSTAINABILITY IN ENERGY AND BUILDINGS, 6., Turin, 2015. Proceedings [...] Turin: Elsiever Procedia, 2016.

OLIVEIRA, R. D.; SOUZA, R. V. G.; DA SILVA, R. M. Issues to be improved on the thermal performance standards for sustainable buildings consolidation: an overview of Brazil. In: INTERNATIONAL CONFERENCE ON SUSTAINABILITY IN ENERGY AND BUILDINGS, 8., Turin, 2016. Proceedings [...] Turin: Elsiever Procedia, 2017.

ORDENES, M. et al. Metodologia utilizada na elaboração da biblioteca de materiais e componentes construtivos brasileiros para simulações no VisualDOE-3.1. Florianópolis: Laboratório de Eficiência Energética de Edificações do Departamento de Engenharia Civil da UFSC, 2003.

PEREIRA, H. A. C. et al. Manual de simulação computacional de edifícios naturalmente ventilados no programa Energyplus - versão 8.0. Florianópolis: Laboratório de Eficiência Energética de Edificações do Departamento de Engenharia Civil da UFSC, 2013.

PEREIRA, I.; FERREIRA, C. Avaliação dos impactos da ABNT NBR 15575 no conforto térmico e no consumo de energias nas novas edificações habitacionais brasileiras. In: ENCONTRO NACIONAL DE TECNOLOGIA DO AMBIENTE CONSTRUÍDO, 15., Maceió, 2014. Anais [...] Maceió: Marketing Aumentado, 2014.

SANTO, A. D.; ALVAREZ, C. E.; NICO-RODRIGUES, E. A. Conforto e desempenho térmico em contradição na NBR 15575. Cadernos PROARQ, v. 20, p. 116-136, 2014. 
SILVA, A. S. et al. Incerteza do método de simulação da NBR 15575-1 para a avaliação do desempenho térmico de habitações. Ambiente Construído, Porto Alegre, v. 14, n. 4, p. 103-117, out./dez. 2014.

SILVA, A. S.; ALMEIDA, L. S. S.; GHISI, E. Análise de incertezas físicas em simulação computacional de edificações residenciais. Ambiente Construído, Porto Alegre, v. 17, n. 1, p. 289-303, jan./mar. 2017.

SORGATO, M. J. et al. Análise do procedimento de simulação da NBR 15575 para avaliação do desempenho térmico de edificações residenciais. Ambiente Construído, Porto Akegre, v. 14, n. 4, p. 83101, out./dez. 2014.

SORGATO, M. J. et al. Nota técnica referente à avaliação para a norma de desempenho NBR 15575 em consulta pública. Florianópolis: Laboratório de Eficiência Energética de Edificações do Departamento de Engenharia Civil da UFSC, 2012.

YANG, L.; YAN, H.; LAM, J. C. Thermal comfort and building energy consumption implications: a review. Applied Energy, v. 115, p. 164-173, 2014.

\section{Agradecimentos}

Os autores agradecem o apoio da Universidade Federal de Mato Grosso do Sul (UFMS) e da Coordenação de Aperfeiçoamento de Pessoal de Nível Superior (CAPES) - Código de Financiamento 001.

\section{Tássio Luiz dos Santos}

Faculdade de Engenharias, Arquitetura e Urbanismo e Geografia | Universidade Federal do Mato Grosso do Sul | Av. Costa e Silva, s/n, Pioneiros | Campo Grande - MS - Brasil | CEP 79070-900 | Tel.: (67) 3345-7378 | E-mail: tassio_cgr@yahoo.com

\section{Fernando Henrique Fiirst dos Santos Porto}

Curso de Arquitetura e Urbanismo | Universidade Católica Dom Bosco | Av. Tamandaré, 6000, Jardim Seminário | Campo Grande - MS Brasil | CEP 79117-010 | Tel.: (67) 3312-3300 | E-mail: fhporto_923@hotmail.com

\section{Arthur Santos Silva}

Faculdade de Engenharias, Arquitetura e Urbanismo e Geografia | Universidade Federal do Mato Grosso do Sul | E-mail: arthurssilva07@gmail.com

\section{Ambiente Construído}

Revista da Associação Nacional de Tecnologia do Ambiente Construído Av. Osvaldo Aranha, 99 - 3o andar, Centro

Porto Alegre - RS - Brasil CEP $90035-190$

Telefone: +55 (51) 3308-4084

Fax: +55 (51) 3308-4054

www. seer. ufrgs. br/ ambienteconstruido

E-mail: ambienteconstruido@ufrgs.br

This is an open-access article distributed under the terms of the Creative Commons Attribution License. 